\title{
خصائص الأيتام الديموغرافية في حضر محافظة واسط )
}

(دراسة في جغرافية السكان )

الباحثة دينا يونس رجا

أ.د ناجي سهم رسن

جامعة واسط /كلية التربية

المستخلص

تهدف الدراسة تناول الأيتام في حضر محافظة واسط من حيث تركيبهم النوعي والعمري التعليمي ونوع

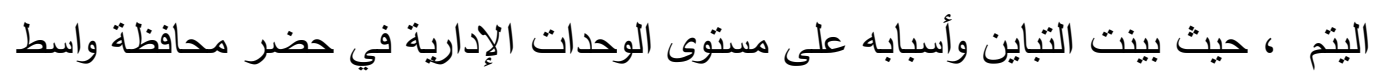
استخدمت الدراسة بعض البيانات المتاحة من خلال مجلس محافظة واسط، مركز المعلومات وبعض

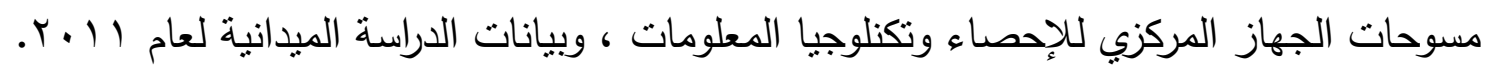

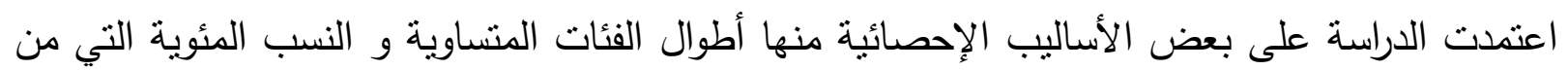
خلالها امكن توزيع قيم الظاهرة بطريقة علمية ، لأجل سهولة المقارنة والتوصل إلى نتائج دقيقة.

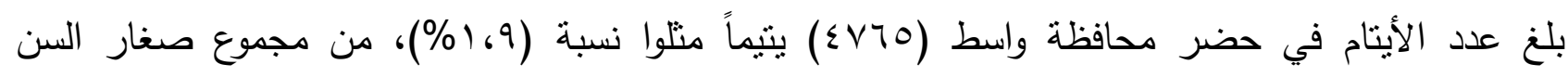

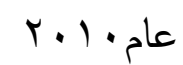

توصلت الدراسة إلى تباين عدد الأيتام ونسبهم على مستوى الوحدات الإدارية في حضر محافظة واسط ، ويرجع ذلك إلى التباين في حجم السكان بين وحدة إدارية وأخرى .

المقدمة

تعد ظاهرة اليتم من الظواهر العالمية اذ لا يخلو منها أي بلد من بلدان العالم ، وان كانت تختلف في

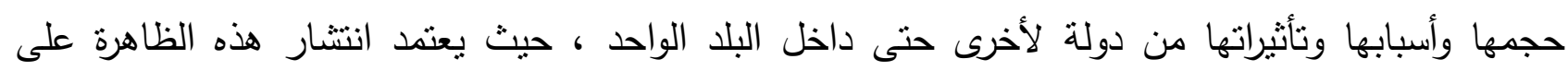

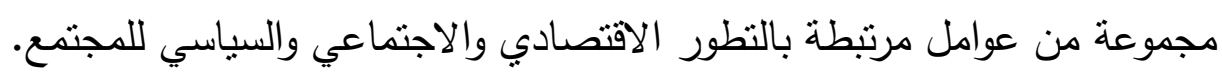

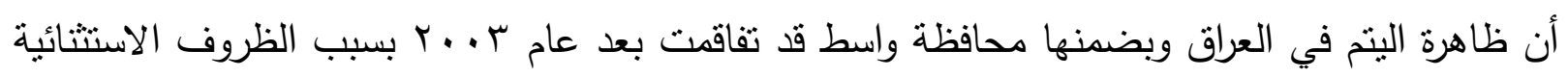

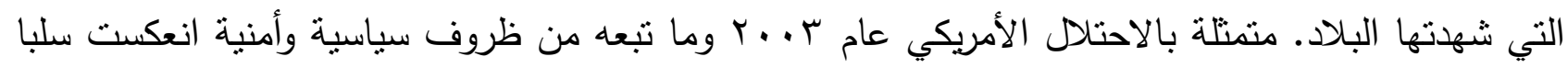


على الواقع الاقتصادي والاجتماعي والسياسي للبلد ، الذي رافقه زيادة عدد الأيتام وارتفاع معدلات الفقر والحرمان مما جعل بعض اسر الأيتام و تضطر إلى دفع بعض أطفاعل أطفالها إلى سوق العمل بسن مبكرة.

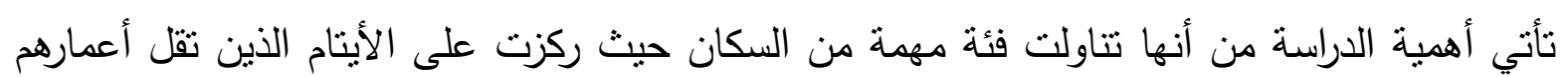

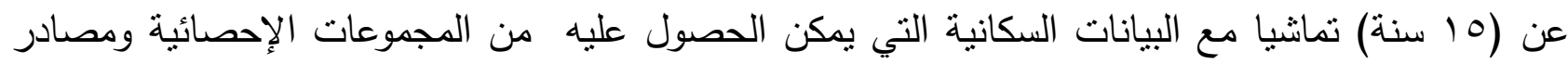

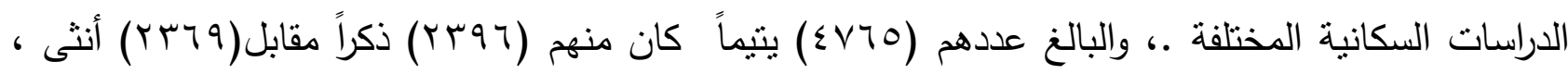
ومثل الأيتام (9, (\%) من مجموع صغار السن في حضر محافظة واسط . .

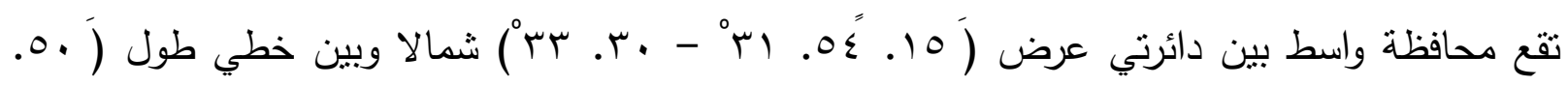

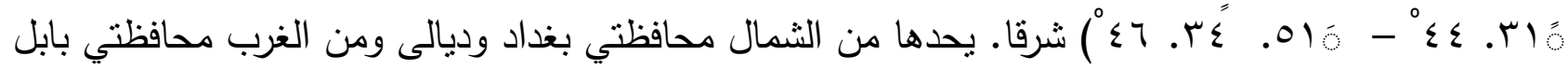
والقادسية ومن الجنوب محافظة ذي قار ومن الجنوب الثرقي محافظة ميسان ومن الثرق ايران خريطة (1).

خريطة (1)

موقع محافظة واسط ووحداتها الإدارية في العراق 


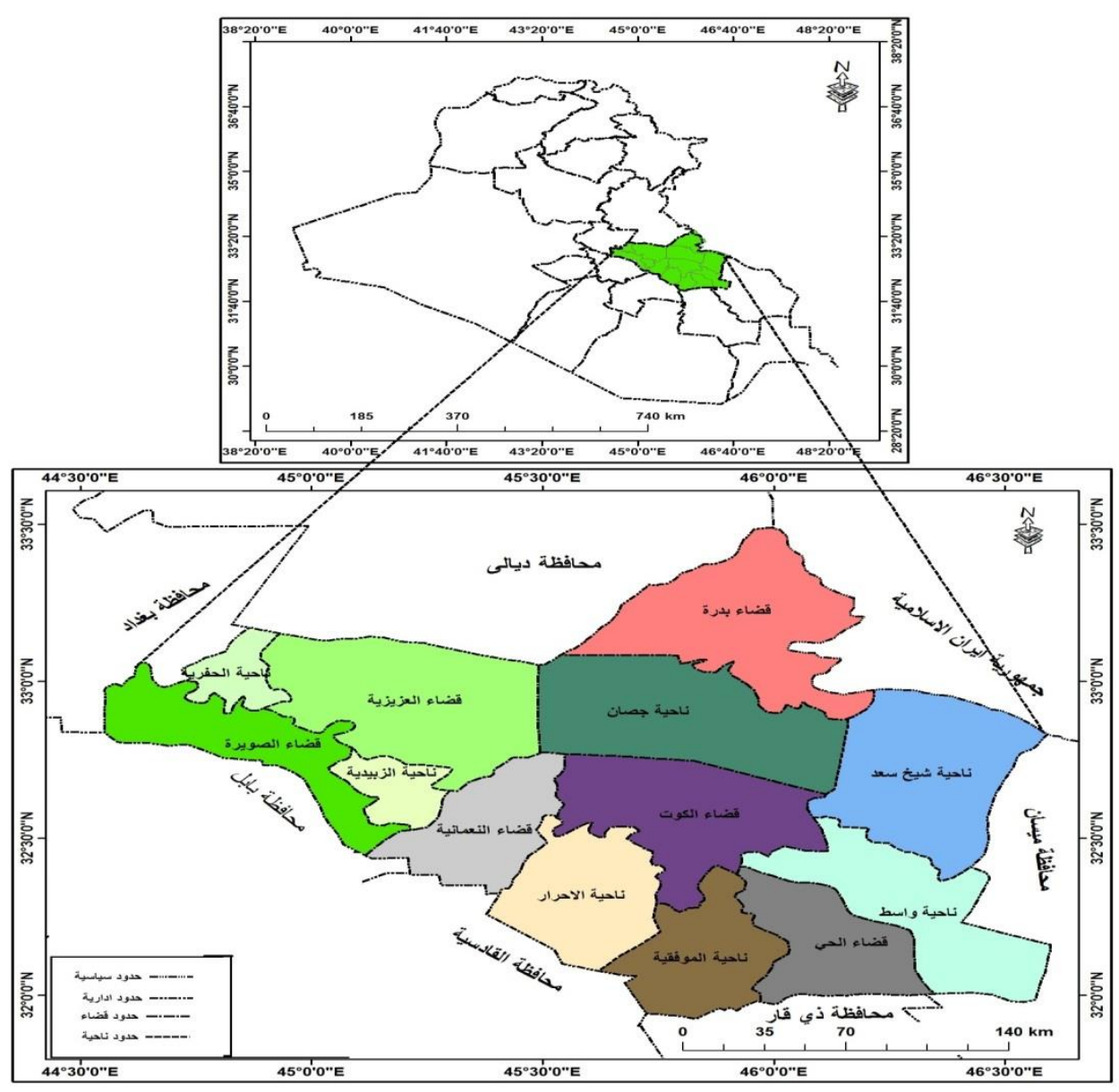

المصدر : وزارة النقل والمواصلات، الهيئة العامة للمساحة، قسم الإنتاج للخرائط الرقمية، بغداد ، العراق، .$r .1$.

ودراسة الأيتام تعد من بين الدراسات التي تستحق الاهتمام والتوجه نحوها كونها تمثل شريحة ليست

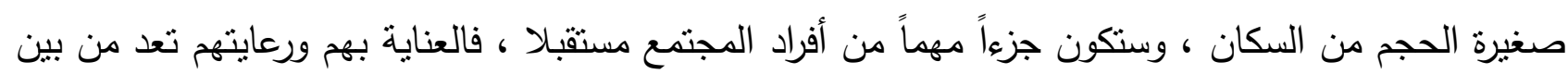
المهام الأساسية التي ينبغي الاهتمام بها من قبل الحكومات والمؤسسات الرسمية وغير الرسمية. 
سوف تقتصر الدراسة على الخصائص الديموغرافية للأيتام متمنلة بالتركيب النوعي والعمري والتركيب التعليمي للأيتام ونوع اليتم لما لها من أهمية في خصائص السكان المختلفة .

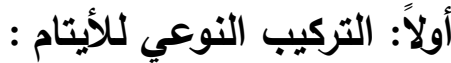

يقصد بالتركيب النوعي أو ما يسمى نسبة النوع تقسيم السكان إلى ذكور وإناث وهي عدد الذكور لكل

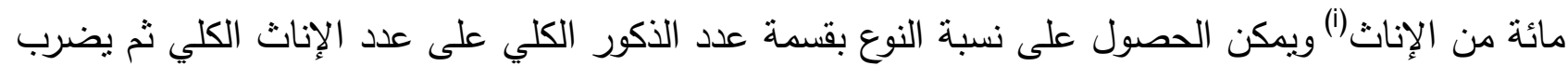

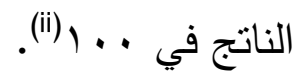

ان دراسة العلاقة بين الذكور والإناث لها أهمية كبيرة تساهم في التعرف على المشاكل الناجمة عن زيادة

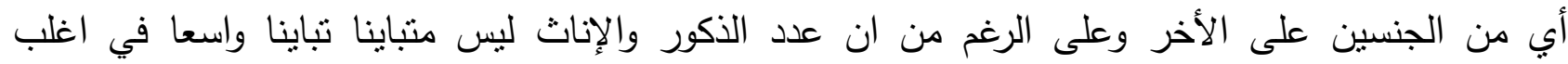

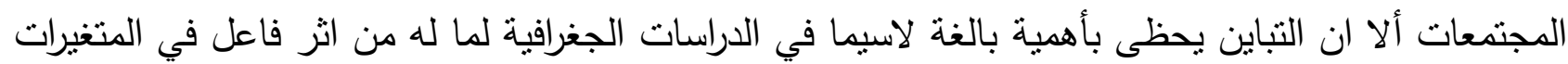
الديموغرافية(iii)

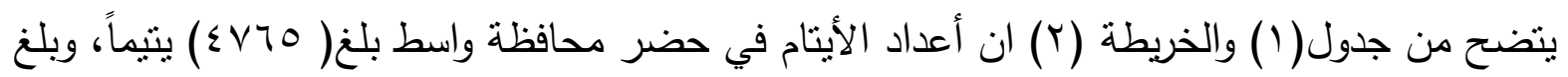

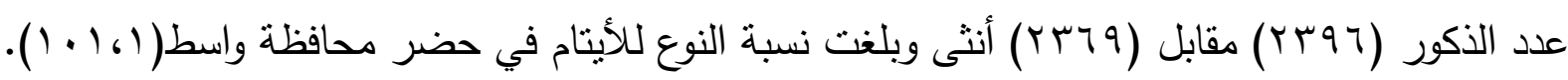

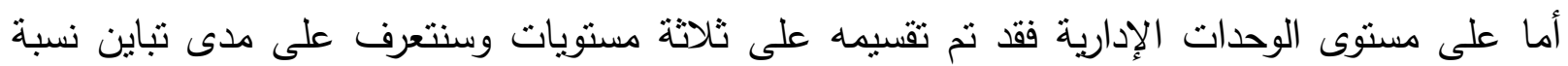

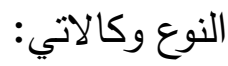

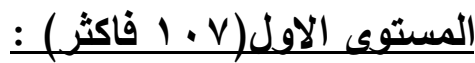

ضم هذا المستوى خمس وحدات إدارية تمثلت في حضر مركز قضاء الكوت وحضر ناحيتي كل من شيخ

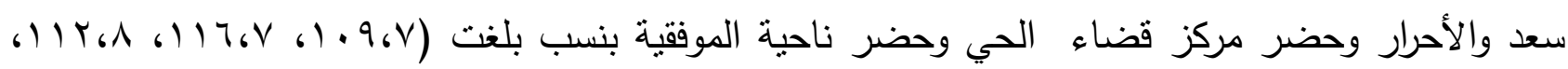

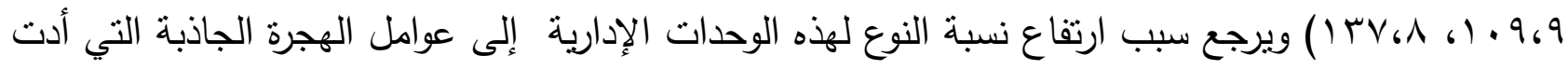

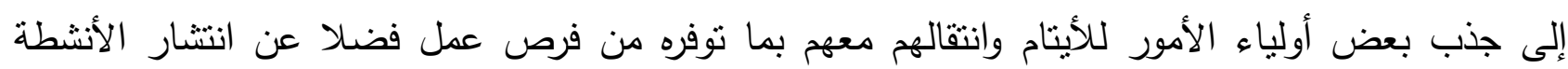

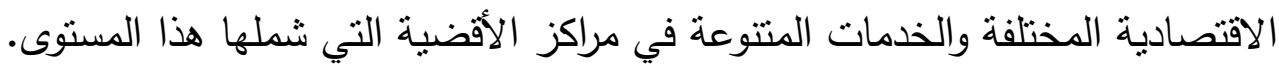

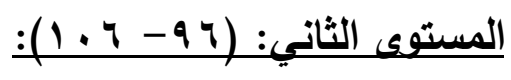

ضم هذا المستوى وحدة إدارية واحدة هي حضر مركز قضاء الصويرة حيث شكل نسبة (1، (9). 
المستوى الثالث (هو فاقّ):

ضم هذا المستوى سبع وحدات إدارية هي حضر ناحية واسط وحضر مركز قضاء النعمانية وحضر ناحية الزبيدية وحضر مركز قضاء العزيزية وحضر ناحية الحفرية وحضر مركز قضاء بدرة وحضر ناحية

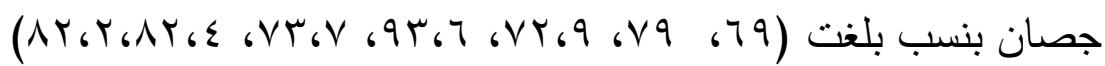

جدول (1)

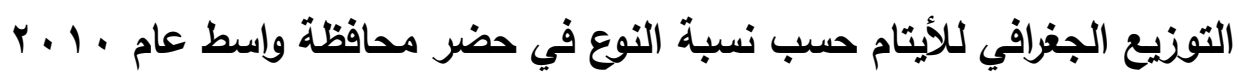

\begin{tabular}{|c|c|c|c|c|}
\hline نسبة النوع & اناث & | ذكور & الوحدات الادارية & $ت$ \\
\hline 1.968 & IrOT & $1 \pi V T$ & مركز قضاء الكوت & 1 \\
\hline 79 & Av & 7. & ناحية واسط & r \\
\hline 117.6 & $\varepsilon r$ & $\leqslant 9$ & ناحية شيخ سعد & $r$ \\
\hline$\vee 9$ & 1.0 & 人r & مركز قضاء النعمانية & $\varepsilon$ \\
\hline$M r_{6} A$ & rq & $\varepsilon \varepsilon$ & ناحية الأحرار & 0 \\
\hline 1.969 & 111 & ITr & مركز قضاء الحي & 7 \\
\hline $1 \mu V_{6}$ A & rv & 01 & ناحية الموفقية & V \\
\hline 91,1 & $10 \leqslant$ & 101 & مركز قضاء الصويرة & $\wedge$ \\
\hline$V r_{6} 9$ & $\vee \cdot$ & 01 & ناحية الزبيدية & 9 \\
\hline 94.7 & ra7 & TVV & مركز قضاء العزيزية & 1. \\
\hline$V r_{6} V$ & $11 \leq$ & $\wedge \varepsilon$ & ناحية الحفرية & 11 \\
\hline$\Delta r_{6} r$ & $\leq 0$ & $r v$ & مركز قضاء بدرة & Ir \\
\hline$\Delta r_{6} \varepsilon$ & IV & $1 \leqslant$ & ناحية جصان & IT \\
\hline 1.161 & rrta & rTat & \multicolumn{2}{|c|}{ المحافظة } \\
\hline$\leqslant \vee \neg 0$ & & & \multicolumn{2}{|c|}{ المجموع الكلي } \\
\hline
\end{tabular}




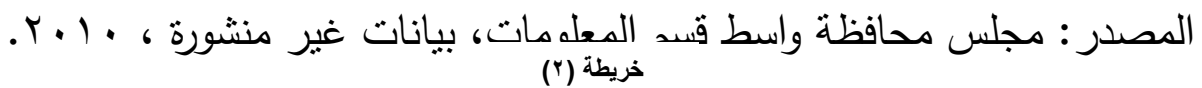

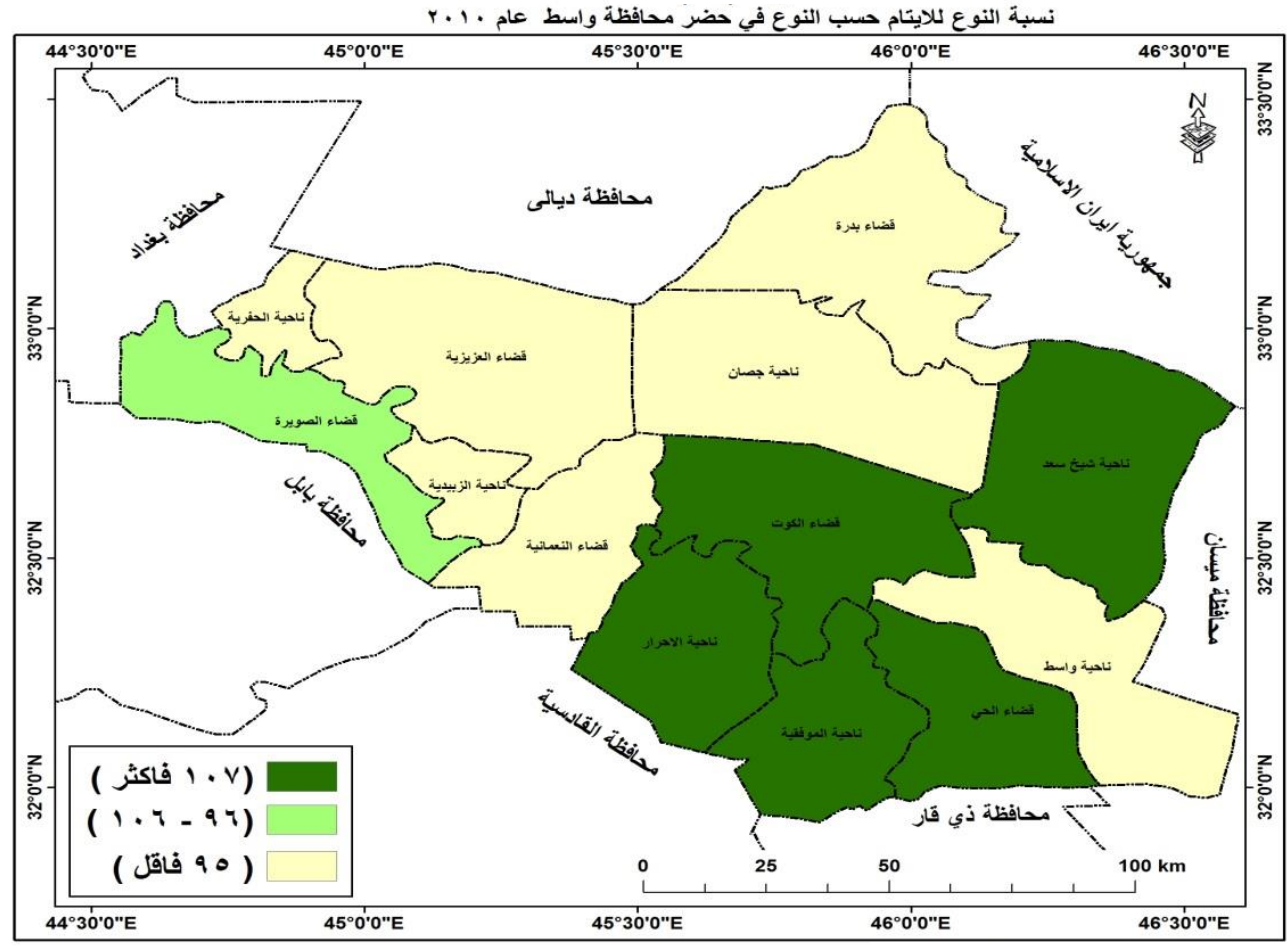

المصدر: بالاعتماد على جدول (1).

كما استقطبت حضر مراكز الأقضية وبعض النواحي أعداد كبيرة من الأيتام المهجرين من مختلف المحافظات العراقية التي تعرضت إلى عدم الاستقرار الأمني الذي شهده العراق منذ سقوط النظام في عام r....، اذ اضطرت معظم الأسر من مختلف أنحاء المحافظات الأكثر تأثرا بالظروف الأمنية بالهجرة إلى

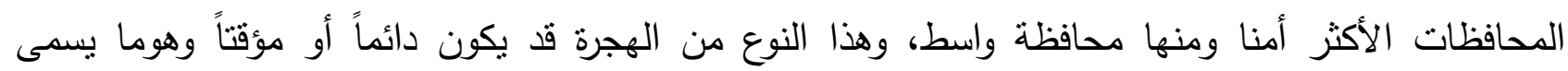
بالهجرة القسرية (iv) حيث تم حصر الأيتام المهجرين القادمين من مختلف المحافظات العراقية إلى حضر محافظة واسط بلغت أعدادهم (T .0) يتيماً بنسبة بلغت (T، • (1\%) من مجموع الأيتام في حضر محافظة واسط(v)، وكانت 
الغالبية العظمى من الأيتام المهرين من محافظة بغداد نظرا لقربها من محافظة واسط من جهة وكون اغلب

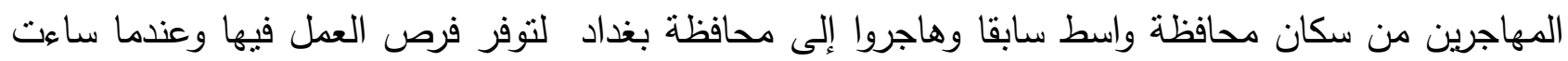

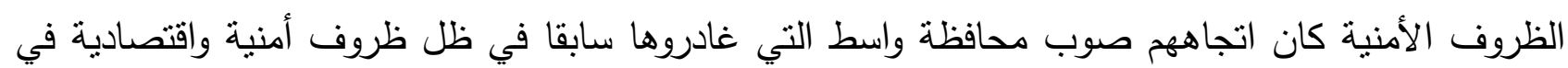

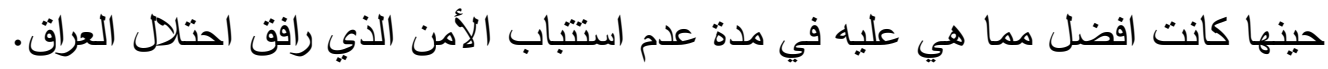

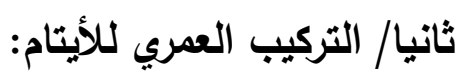
يقصد بالتركيب العمري للسكان تصنيفهم بحسب فئات العمر والتركيب العمري يحظى بأهمية كبيرة لما له من تأثثر بارز في المستويات الديموغرافية بوصفه محصلة لها ، ودلالة أساسية في قياس وحساب مؤشراتها،

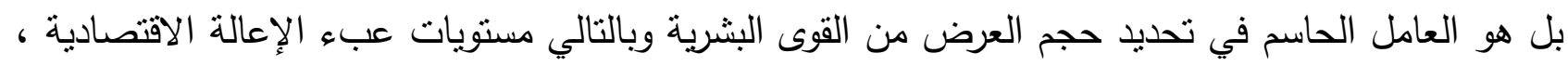

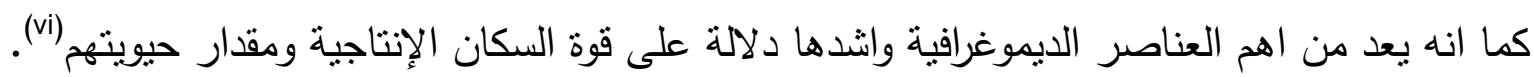

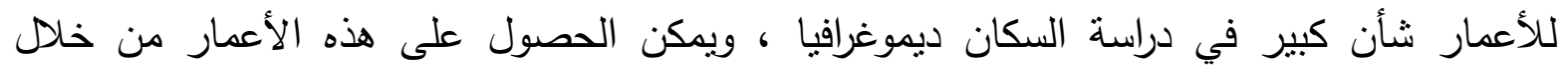

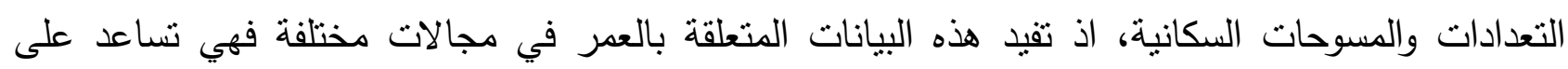

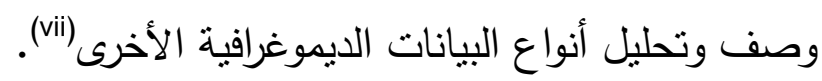

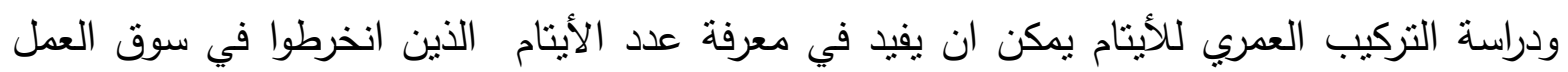

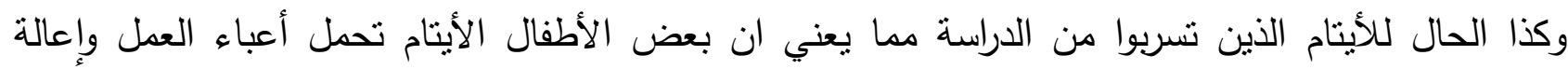

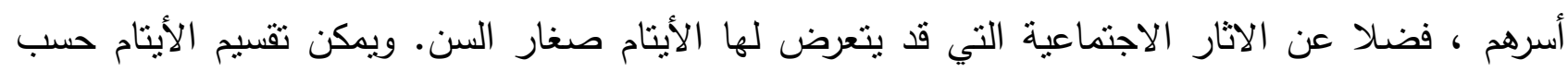

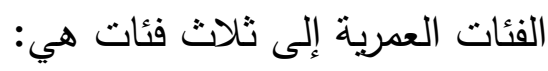

$$
\begin{aligned}
& \text { ا. بئة (اقل من 0) سنة. } \\
& \text { r. فئة (0-9) (9نة. }
\end{aligned}
$$

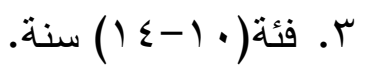

وتمثل هذه الفئات الثناث (اقل من أنة 10) سنة قاعدة الهرم السكاني لأي مجتمع حيث ترتكز عليها أعداد الفئات العمرية وتتصف بكونها مستهلكة وغير منتجة.

$$
\text { ا. فئة (اقل من ه) سنة. }
$$


أجريت في محافظة واسط تقديرات سكانية حسب الفئات العمرية لسنة . 1 • ب، وكانت أعداد فئة (اقل

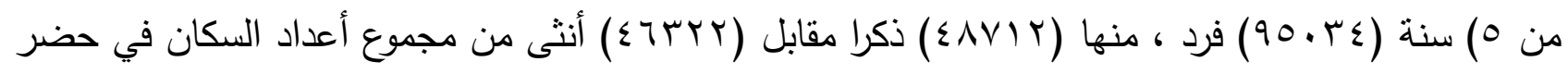

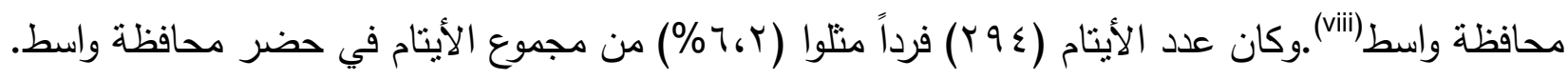
وتعد هذه الفئة العدرية من اكثر الفئات تأثرا بعامل الوفيات مما أدى إلى انخفاض نسبتها اذا تم مقارنتها بالفئات العمرية الأخرى، وظهر تباين في توزبعها على مستوى الوحدات الإدارية في حضر محافظة واسط وكما يتضح من الجدول (r) والخريطة(r) الذي تم فيه حصر ثلاثة مستويات وكالاتي:

جدول(r)

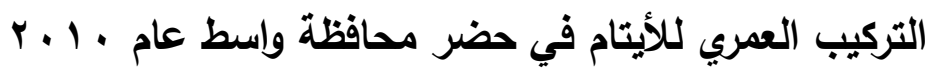

\begin{tabular}{|c|c|c|c|c|c|c|c|c|c|}
\hline \multicolumn{2}{|r|}{ المجموع } & \multicolumn{2}{|c|}{ 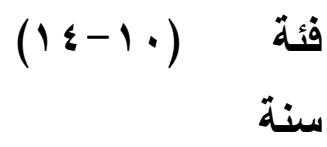 } & \multicolumn{2}{|c|}{ فئة (0-9) سنة } & \multicolumn{2}{|c|}{ فئة (اقلة من م م) } & \multirow{2}{*}{ الادارية } & \multirow[t]{2}{*}{ ت } \\
\hline$\%$ & عدد & $\%$ & عدد & $\%$ & عدد & $\%$ & عدد & & \\
\hline $1 \ldots$ & YYYo & 7161 & $17 \cdot \varepsilon$ & r & $\Lambda \vee q$ & 0 ، 2 & $1 \leqslant Y$ & مركز قضاء & 1 \\
\hline $1 \ldots$ & $1 \leqslant V$ & 7.60 & 19 & r & $\varepsilon 7$ & $\Lambda_{6} r$ & Ir & ناحية واسط & r \\
\hline $1 \ldots$ & 91 & $\varepsilon 7.6$ & $\varepsilon Y$ & $\& 7, Y$ & $\varepsilon Y$ & $V_{6} 7$ & V & ناحية شيخ & r \\
\hline $1 \cdots$ & $1 \wedge 1$ & $7 r_{6} \Lambda$ & 111 & Mr. & 71 & $\varepsilon, \Lambda$ & 9 & مركز & $\varepsilon$ \\
\hline $1 \cdots$ & $\Lambda \mu$ & $0 \mu_{6} 1$ & $\varepsilon \varepsilon$ & rV.r & r & 967 & $\Lambda$ & ناحية الاحرار & 0 \\
\hline
\end{tabular}


العدد الرابع عشر

مجلة كلية التربية / واسط

\begin{tabular}{|c|c|c|c|c|c|c|c|c|c|}
\hline $1 \cdots$ & rMr & 07.4 & $|r|$ & r، اس & Vr & $1 r_{6} 0$ & rq & مركز قضناء & 7 \\
\hline $1 \cdots$ & $\Lambda \wedge$ & $0 V_{6} q$ & 01 & $r \varepsilon_{6} r$ & $\mu$ & $V_{6} 9$ & V & الموفية & $v$ \\
\hline $1 \cdots$ & r. o & O & IVY & rV. I & 114 & 7.7 & $r$. & مركز قضاء & $\wedge$ \\
\hline $1 \cdots$ & $|r|$ & $07, \mu$ & 71 & $\mu \Lambda_{6} \Lambda$ & $\varepsilon V$ & $\varepsilon 69$ & 7 & ناحية الزبيدية & 9 \\
\hline $1 \cdots$ & OVT & 0761 & MrI & $\mu \Lambda_{6} \Lambda$ & rrr & 0,1 & rq & مركز & 1. \\
\hline $1 \cdots$ & 191 & 07.7 & $11 r$ & س، & 77 & 1.61 & $r$. & ناحية الحفرية & 11 \\
\hline $1 \cdots$ & $\Lambda Y$ & 07.1 & $\leqslant 7$ & $r q, 1$ & rr & $\varepsilon_{6} \wedge$ & $\varepsilon$ & مركز قضاء & Ir \\
\hline $1 \cdots$ & M & $\left\{\Lambda_{6} \leqslant\right.$ & 10 & $\varepsilon \Lambda_{6} \varepsilon$ & 10 & $r_{6} r$ & 1 & ناحية جصان & r \\
\hline $1 \cdots$ & $\varepsilon \vee 70$ & 0961 & $Y \wedge \mid r$ & $r \varepsilon_{6} V$ & 1701 & $7 . Y$ & rqs & المجموع & \\
\hline
\end{tabular}

المصدر : مجلس محافظة واسط ، قسم المعلومات، بيانات غير منشورة، ب ب 
خريطة (r)

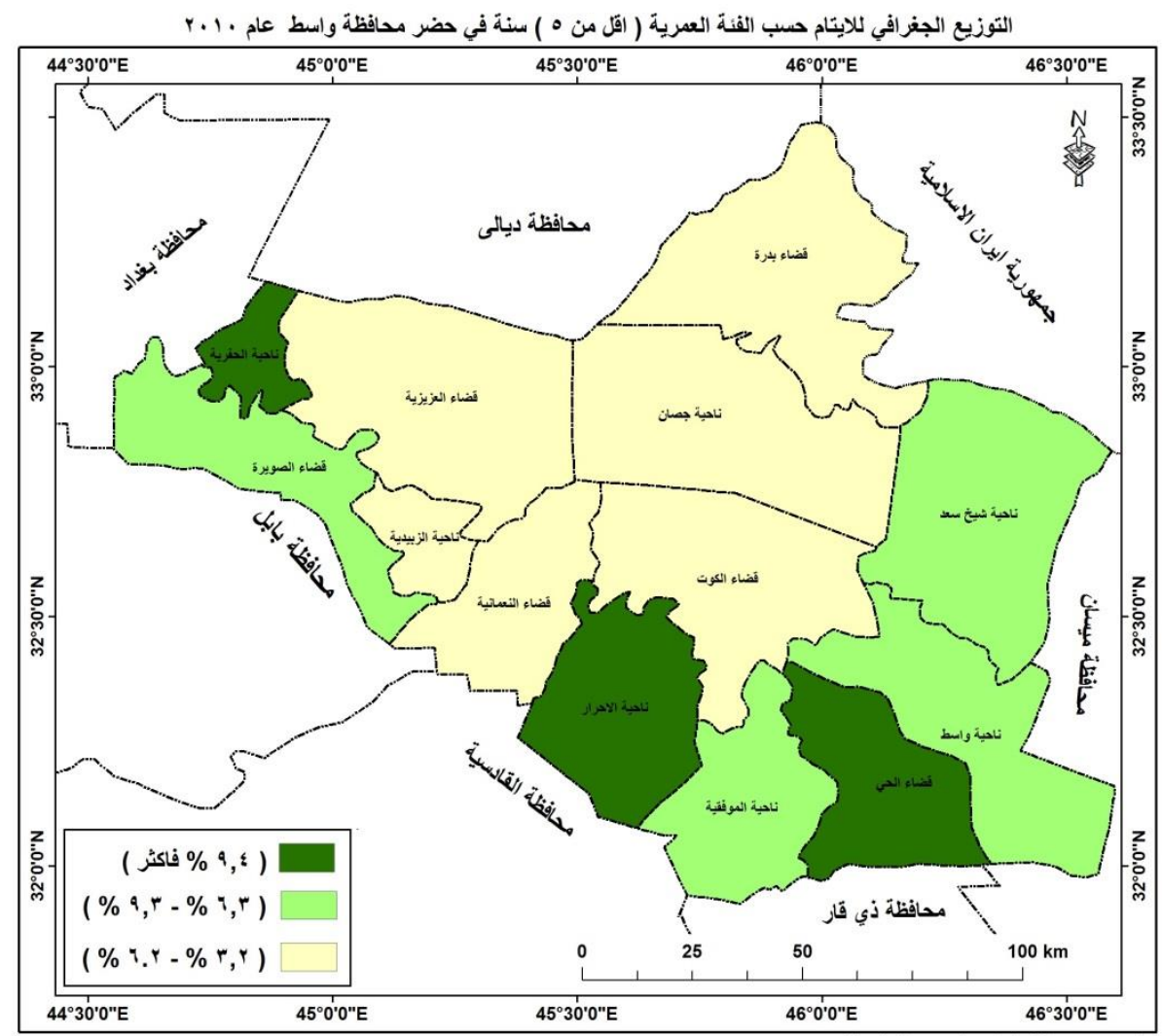

المصدر :بالاعتماد على جدول (r)

المستوى الاول (ع، 9 \% فاكثر)

ضم هذا المستوى ثلاث وحدات إدارية تمثلت في حضر ناحيتي الأحرار والحفرية وحضر مركز قضاء الحي

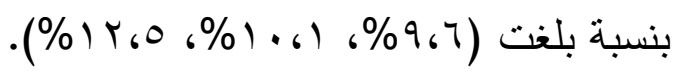

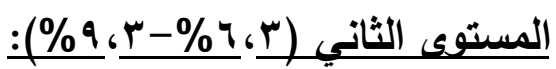

ضم هذا المستوى اربع وحدات إدارية تمثلت في حضر مركز قضاء الصويرة وحضر نواحي شيخ سعد

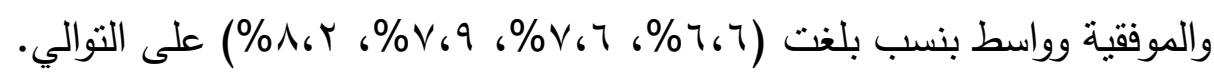

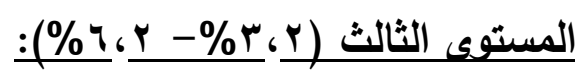

ضم هذا المستوى ست وحدات إدارية تمثلت في حضر ناحية جصان وحضر مركز قضاءي بدرة والنعمانية

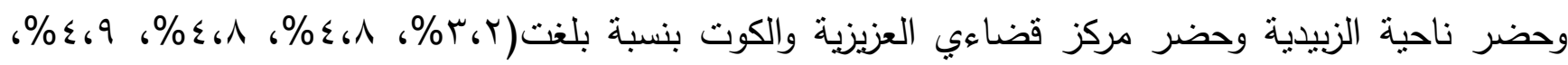

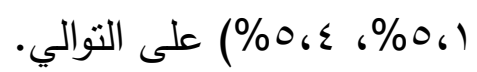




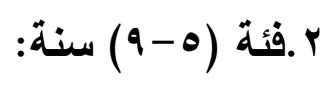

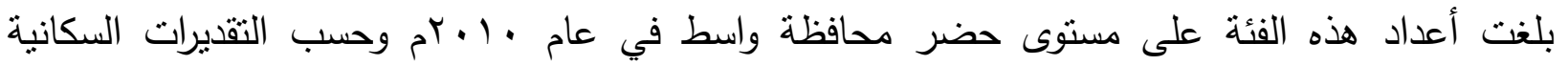

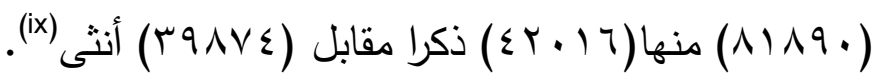

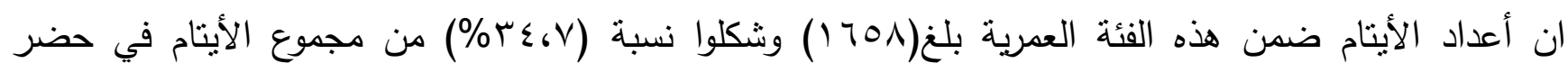

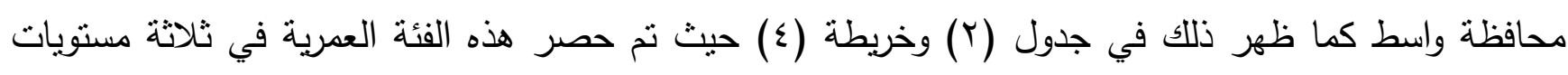
وكالاتي:

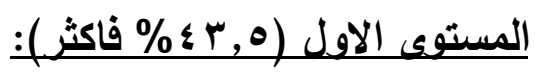

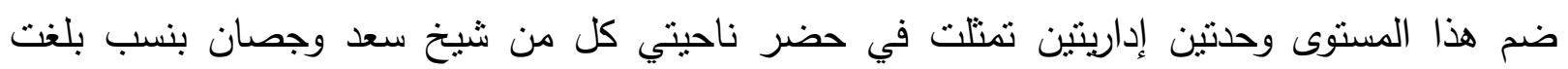

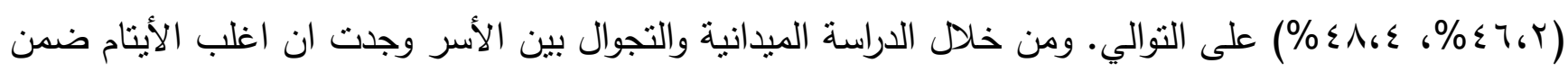

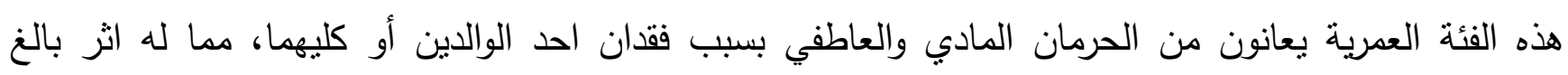
الخطورة على نفسية اليتيم في المستقبل.

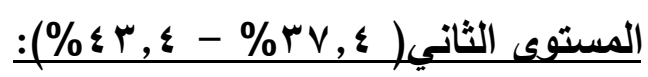

ضم هذا المستوى ثلاث وحدات إدارية تنثلت في حضر ناحية الزبيدية ومركز قضائي كل من العزيزية

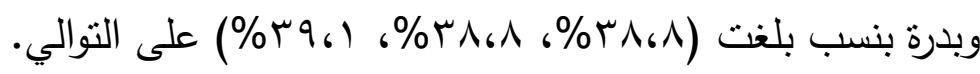

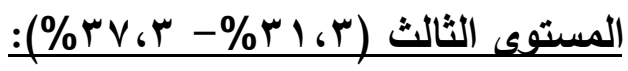

ضم هذا المستوى ثمان وحدات إدارية تنثلت في حضر مركز قضاء الحي وحضر ناحية واسط وحضر مركز قضاء النعمانية وحضر ناحية الحفرية وحضر مركز قضاء الكوت وحضر ناحية الموفقية وحضر مركز

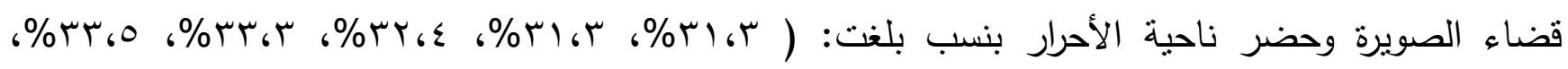

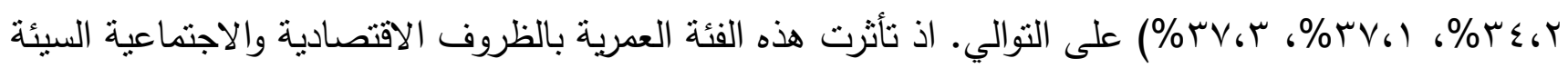

خريطة (0) 


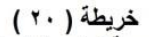

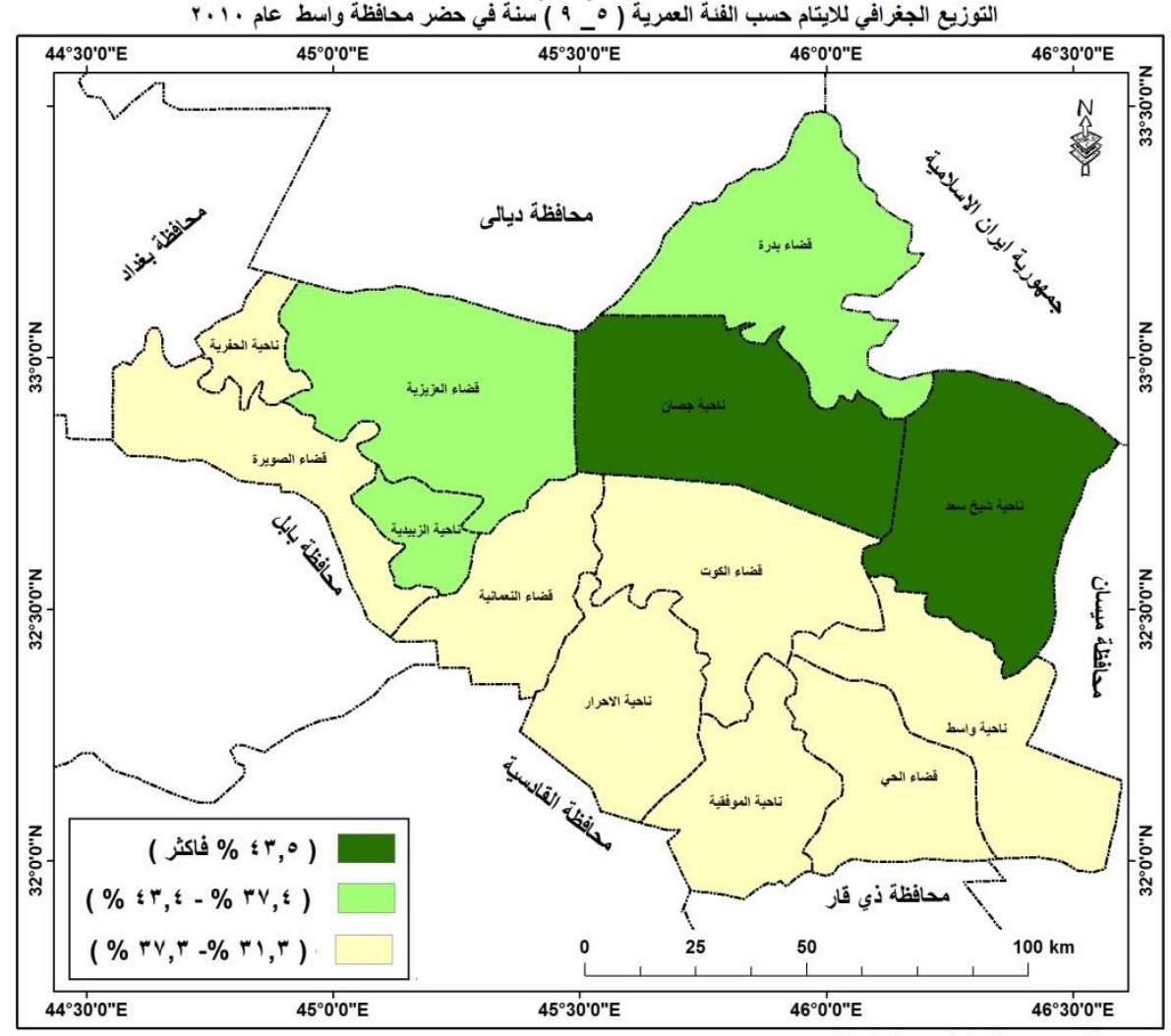

المصدر: بالاعتماد على جدول (r)

المحيطة بهم ، حيث حرم بعض الايتام ضمن هده الفُّه العمريه من ممارسة حقهم بالتعلم، فضلا عن غياب معيلي الأسرة مما أدى إلى زج بعض الأيتام من الذكور إلى سوق العمل على الرغم من صغر سنهم وضعف بنيتهم الجسمية ، مما أدى إلى امتهانهم مهناً هامشية تدر عليهم بالربح القليل الذي يساهم في سد جزء من متطلبات

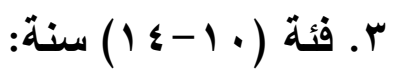

بلغت أعداد هذه الفئة العدرية على مستوى حضر محافظة واسط في عام • ( • ب، وحسب التقديرات السكانية

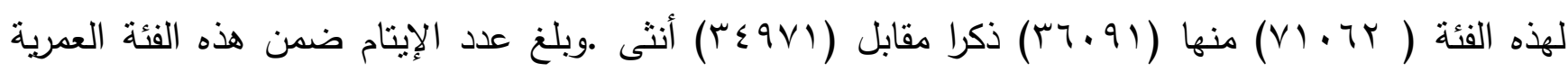

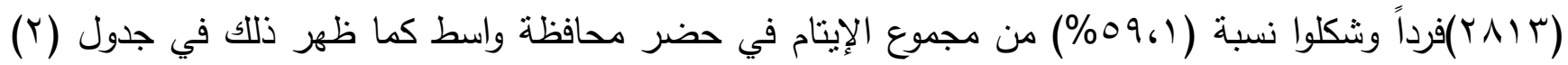
وخريطة(0) حيث تم حصرهم في ثلاثة مستويات وكالاتي:

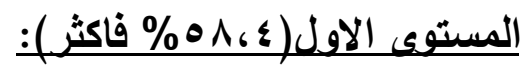


ضم هذا المستوى ثلاث وحدات إدارية تمثلت في حضر ناحية واسط وحضر مركز قضائي الكوت والنعمانية

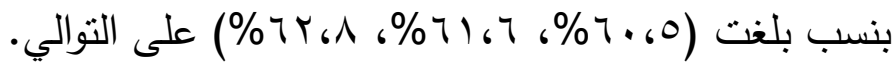

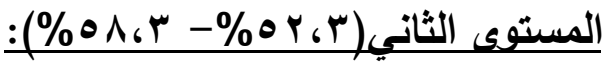

ضم هذا المستوى حضر ناحية الأحرار وحضر مراكز أقضية كل من بدرة والعزيزية والحي والصويرة وحضر

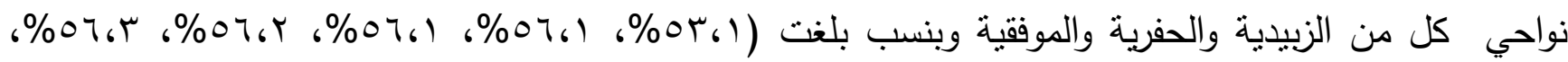

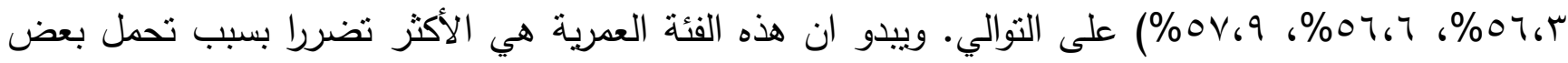

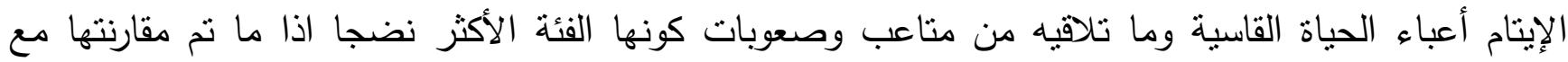

خريطة (0) الفئتين السابقتين.

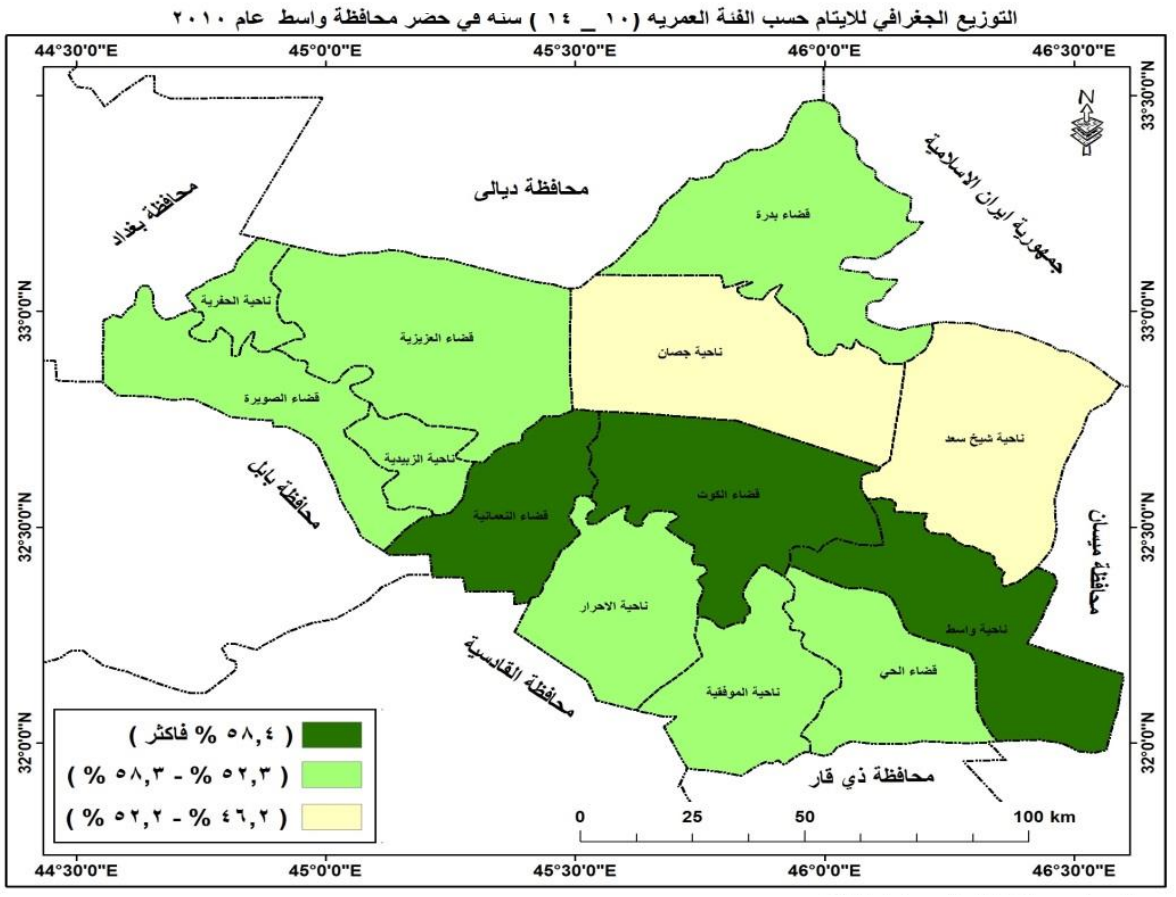

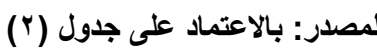

المستوى الثالث (r)

ضم هذا المستوى وحدتين إداريتين تمثلت في حضر ناحيتي كل من شيخ سعد وجصان بنسب

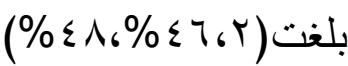

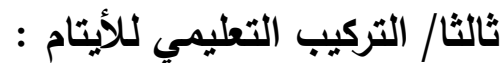


يقصد بالتركيب التعليمي توزيع السكان بحسب الحالة التعليمية وتتبثق أهية بياناته من كونها تعد مؤشرا

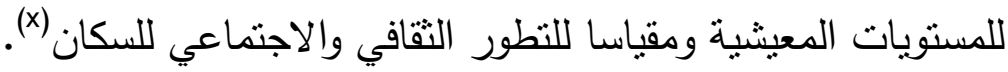

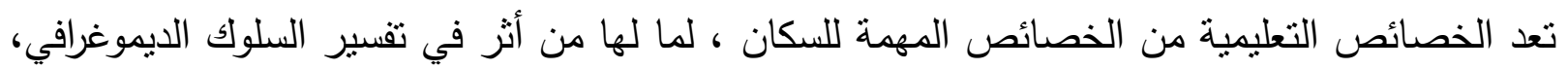

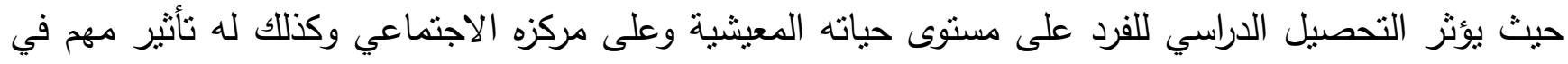

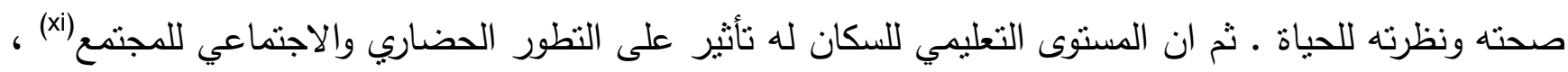
ويرتبط تقسيم السكان بالتركيب التعليمي حسب مستوى التعليم والعمر والنوع لما له من أهمية في تحديد قدرة البلد

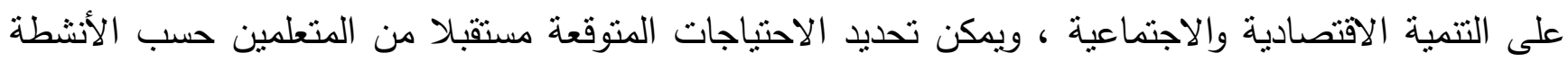

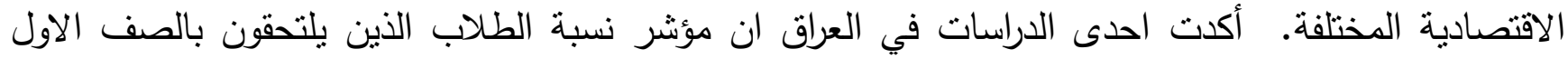

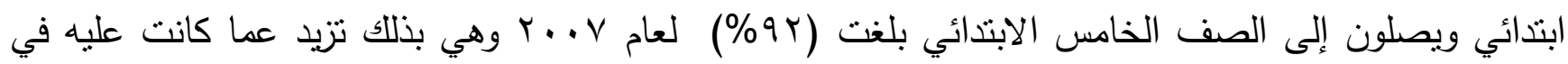

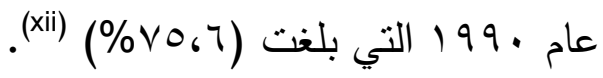
أما بالنسبة للأينام في العراق ومنها محافظة واسط وبسبب الظروف الاقتصادية والاجتماعية فقد لا يحظون

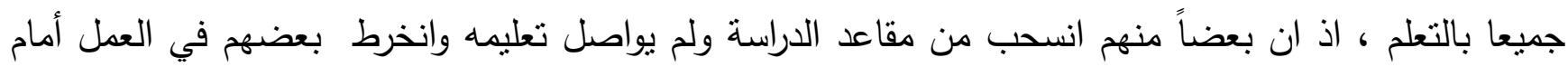

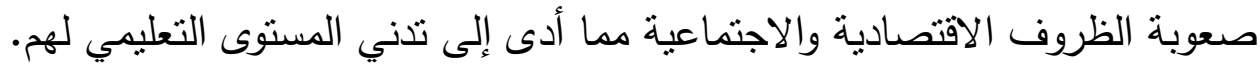

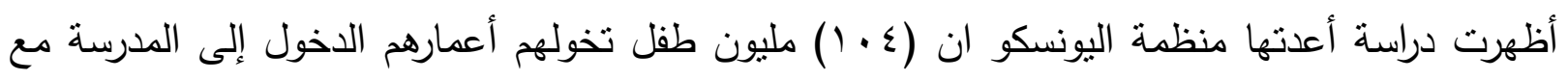

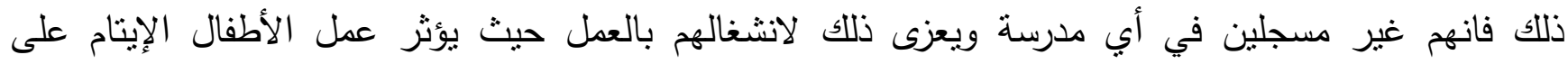
التحصيل العلمي لعدد كبير من الأطفال الذين يعملون ويدرسون في الوقت نفسه وفي معظم الأوقات يترك الأطفال

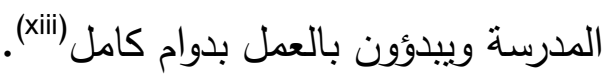
تبين من خلال الدراسة الميدانية في حضر محافظة واسط ، معرفة اهم أسباب عدم إكمال بعض الإيتام

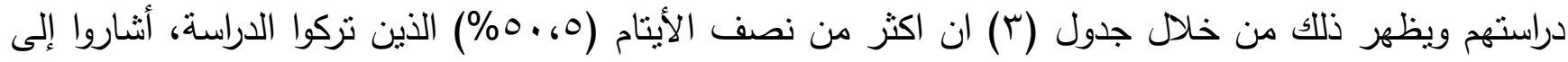
انهم تركوا الدراسة لأسباب اقتصادية وتمثلت في (الفقر والعوز المادي).

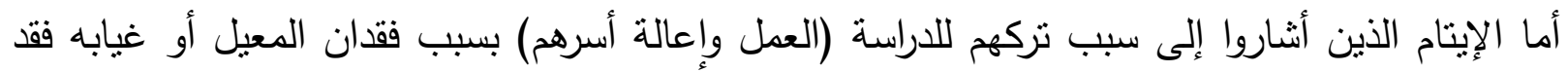

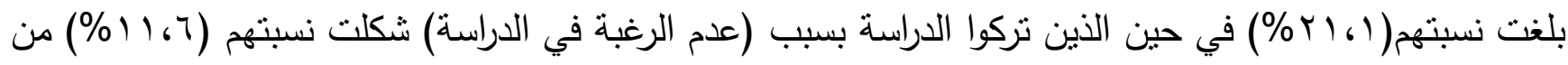
مجموع الإيتام الذين تركوا الدراسة. أما الإيتام الذين أثناروا إلى (سوء الأوضاع الأمنية) التي كانت سبياً رئيساً في نركهم الدراسة فقد شكلوا

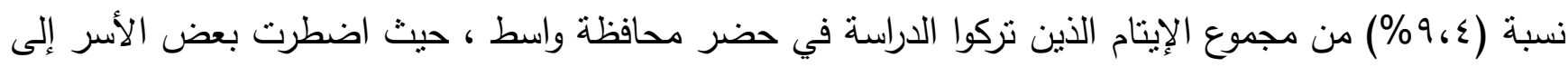
إجبار أبنائها على نرك الدراسة وهذا يصدق في كثير من الأحيان على الأسر المهجرة إلى حضر محافظة واسط 
أما الإيتام الذين تركوا الدراسة بسبب(بعد المدرسة عن منازلهم) وهم يقصدونها سيراً على الأقدام وغالباً يقطن

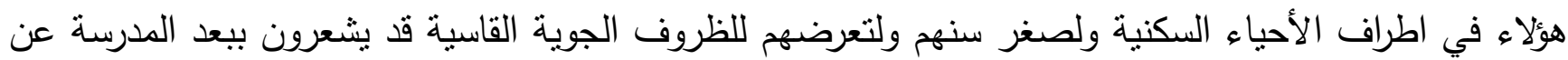

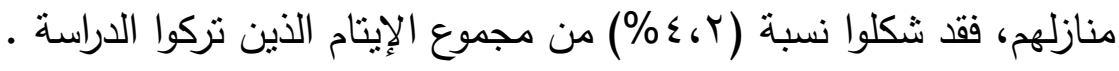

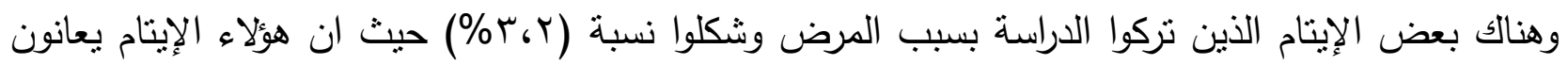

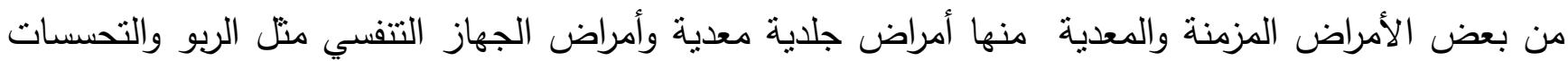

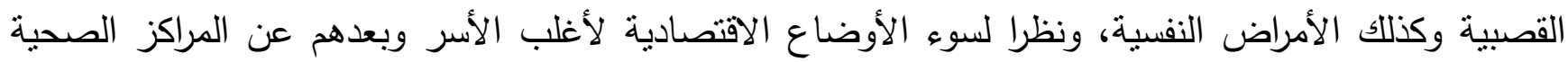

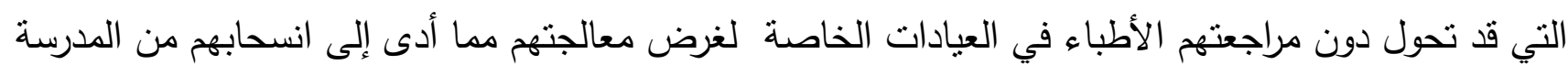

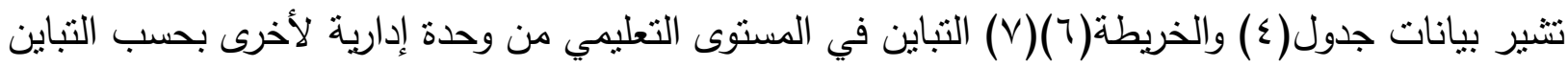

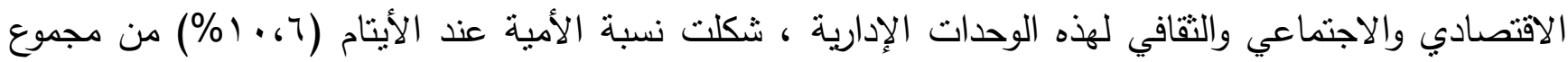

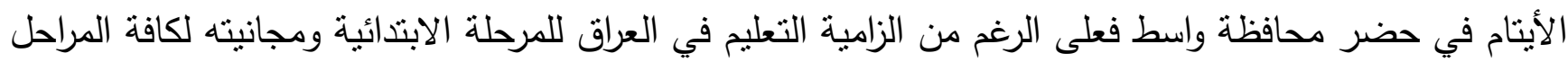

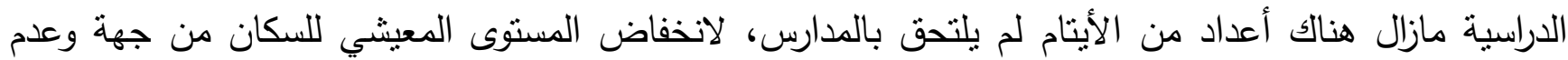

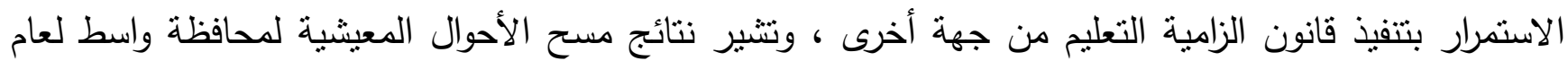

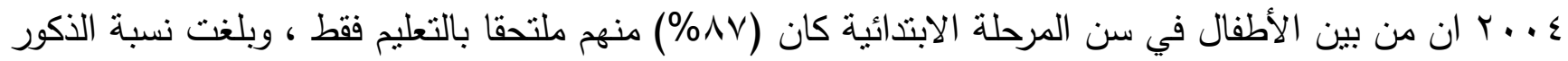

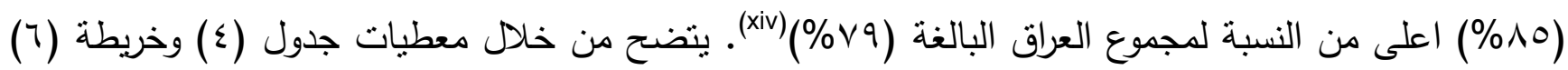
(V)

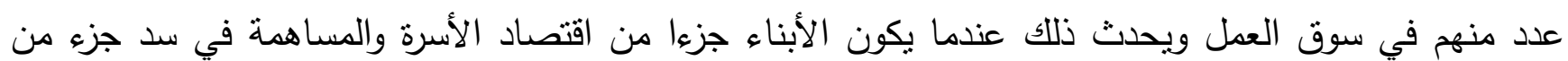

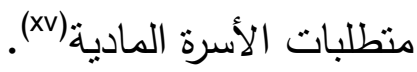

جدول (r) منداب (ب)

أسباب ترك الأيتام الاراسة في حضر محافظة واسط عام 11 بـ

\begin{tabular}{|c|c|c|c|}
\hline$\%$ & عدد & أسباب ترك الدراسة & ت \\
\hline 0.60 & $\varepsilon \wedge$ & الفقر والعوز المادي & 1 \\
\hline Y1. & r. & العمل وإعالة أسرهم & r \\
\hline 11.7 & 11 & عدم الرغبة في الدراسة & $r$ \\
\hline $9 ، \varepsilon$ & 9 & سوء الوضع الأمني & $\varepsilon$ \\
\hline$\varepsilon_{6} r$ & $\varepsilon$ & بعد المدرسة عن المنزل & 0 \\
\hline
\end{tabular}




\begin{tabular}{|r|r|r|r|}
\hline r.r & $r$ & $T$ \\
\hline $1 .$. & 90 & & \\
\hline $1, r$ & & \\
\hline & & \\
\hline
\end{tabular}

المصدر : الدراسة الميدانية . المكات

كما أكدت احدى الدراسات في محافظة واسط ان نسبة الأيتام العاملين في حضر محافظة واسط بلغت (xvi) ( كما ان الإرهاب هو الأخر ساهم في انسحاب الأيتام من الدقاعد الدراسية (xvii)، اذ ان التهجير القسري

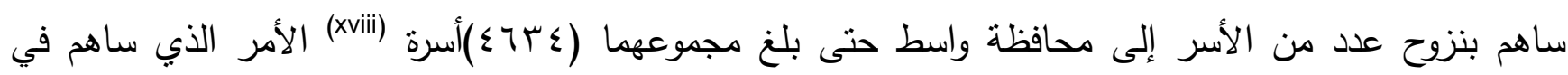

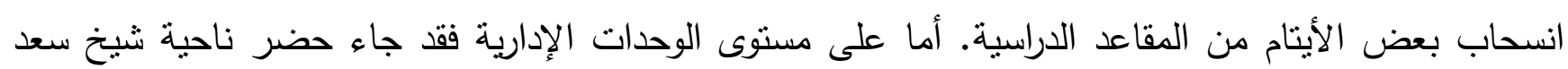

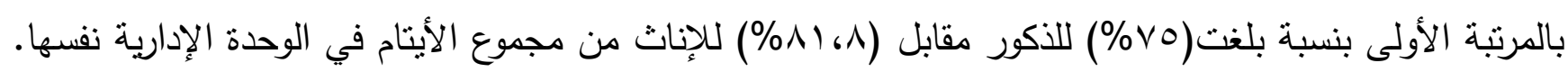

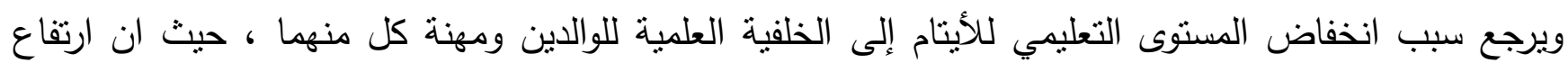
نسبة الأمية لاى والدي اليتيم ينعكس اثنره على الأطفال وعدم تتجيعهم على إكمال الدراسة فانهم يرون عملية

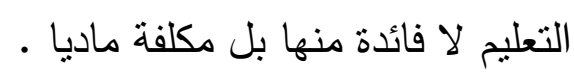




\section{جدول(ई) (- ()}

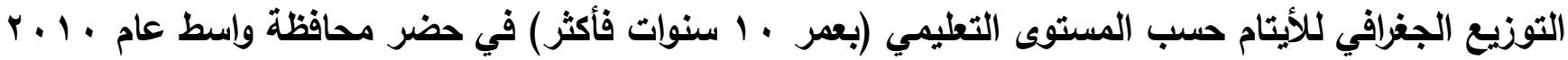

\begin{tabular}{|c|c|c|c|c|c|c|c|c|c|c|c|c|c|c|c|c|c|c|c|c|c|}
\hline & & & المجمو & & & & متوس & & & & ابتدائي & & & & يقرا و & & & & امي & & \\
\hline & اناث & & ذكور & & اناث & & ذكور & & اناث & & ذكور & & اناث & & ذكور & & اناث & & ذكور & & $ت$ \\
\hline$\%$ & عدد & $\%$ & عدد & $\%$ & عدد & $\%$ & عدد & $\%$ & عدد & $\%$ & عدد & $\%$ & عدد & $\%$ & عدد & $\%$ & عدد & $\%$ & عدد & & \\
\hline $1 \ldots$ & VTV & $1 \ldots$ & Arv & 11,4 & 14 & 11,0 & 97 & $V Y_{6} \theta$ & 004 & $\vee 4_{6} \Lambda$ & $T \leqslant r$ & 9.0 & $V r$ & $V .7$ & צ & 7,1 & Or & $\varepsilon_{6} 1$ & $\Gamma \varepsilon$ & مركز & 1 \\
\hline $1 \ldots$ & 01 & $1 \ldots$ & rᄉ & $r . q$ & $r$ & r. T & 1 & ع & 17 & $r q_{10}$ & 10 & 11,1 & 7 & 1.60 & $\varepsilon$ & or، $q$ & $r V$ & $\varepsilon V_{6} \varepsilon$ & 11 & ناحية واسط & r \\
\hline $1 \ldots$ & $r r$ & $1 \ldots$ & $r$. & - & - & - & - & $1 \Lambda_{6} r$ & $\varepsilon$ & 10 & $r$ & - & - & 1. & $r$ & 11,1 & 11 & vo & 10 & سعدية شيخ & $r$ \\
\hline $1 \ldots$ & TY & $1 \ldots$ & 07 & 9.7 & 7 & $\Lambda_{6} 9$ & 0 & T: & $\varepsilon$. & 74.1 & rv & 7.0 & $\varepsilon$ & $\left.V_{6}\right)$ & $\varepsilon$ & $196 \varepsilon$ & Ir & $1 V_{6} 9$ & 1. & مركز قضاء & $\varepsilon$ \\
\hline $1 \ldots$ & 11 & $1 \ldots$ & rq & 17.6 & $r$ & 10,4 & $\varepsilon$ & \& \& ، & $\wedge$ & Vr. & 19 & 11,1 & $r$ & $r . q$ & 1 & $r V_{6} A$ & 0 & $V_{6} v$ & $r$ & ناحية الاحرار & 0 \\
\hline $1 \ldots$ & 71 & $1 \ldots$ & $v$. & r.r & Y & $0, \mathrm{~V}$ & $\varepsilon$ & $\leqslant 0,9$ & $r \wedge$ & 0. & ro & $r V_{6} r$ & IV & $r V_{6} r$ & 19 & rr.q & $1 \leq$ & $1 v_{6} \mid$ & Ir & مركز قضاء & 7 \\
\hline $1 \ldots$ & ro & $1 \ldots$ & rT & Ir & $r$ & $V_{6} v$ & r & 41 & IV & or، 9 & $1 \varepsilon$ & $\varepsilon$ & 1 & $r_{6} \Lambda$ & 1 & 17 & $\varepsilon$ & T & 9 & ناحية الموفقية & V \\
\hline $1 \ldots$ & Ar & $1 \ldots$ & 19 & \& \& 1 & Ir & 9 & $\wedge$ & 94.9 & or & 1.69 & $V Y$ & r.t & $r$ & 0,7 & 0 & $11_{6} 1$ & 10 & $\varepsilon_{0} 0$ & $\varepsilon$ & مركز $\quad$ قضاء & $\wedge$ \\
\hline $1 \ldots$ & $r v$ & $1 \ldots$ & $r_{1}$ & $r 9 . \mathrm{V}$ & 11 & rq & 9 & A & rI & 0, 1 & $r$. & - & - & - & - & $1 \pi, 0$ & 。 & 7.0 & $r$ & ناحية الزبيدية & 9 \\
\hline
\end{tabular}




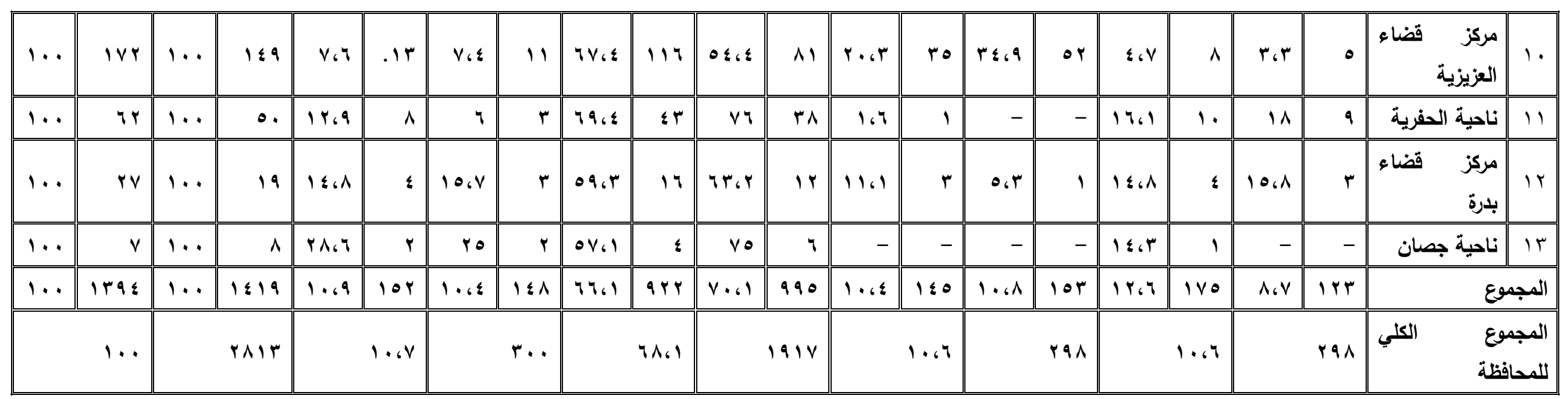

المصدر : مجلس محافظة واسط ، قسم المعلومات، بيانات غير منشورة، 1 ب 

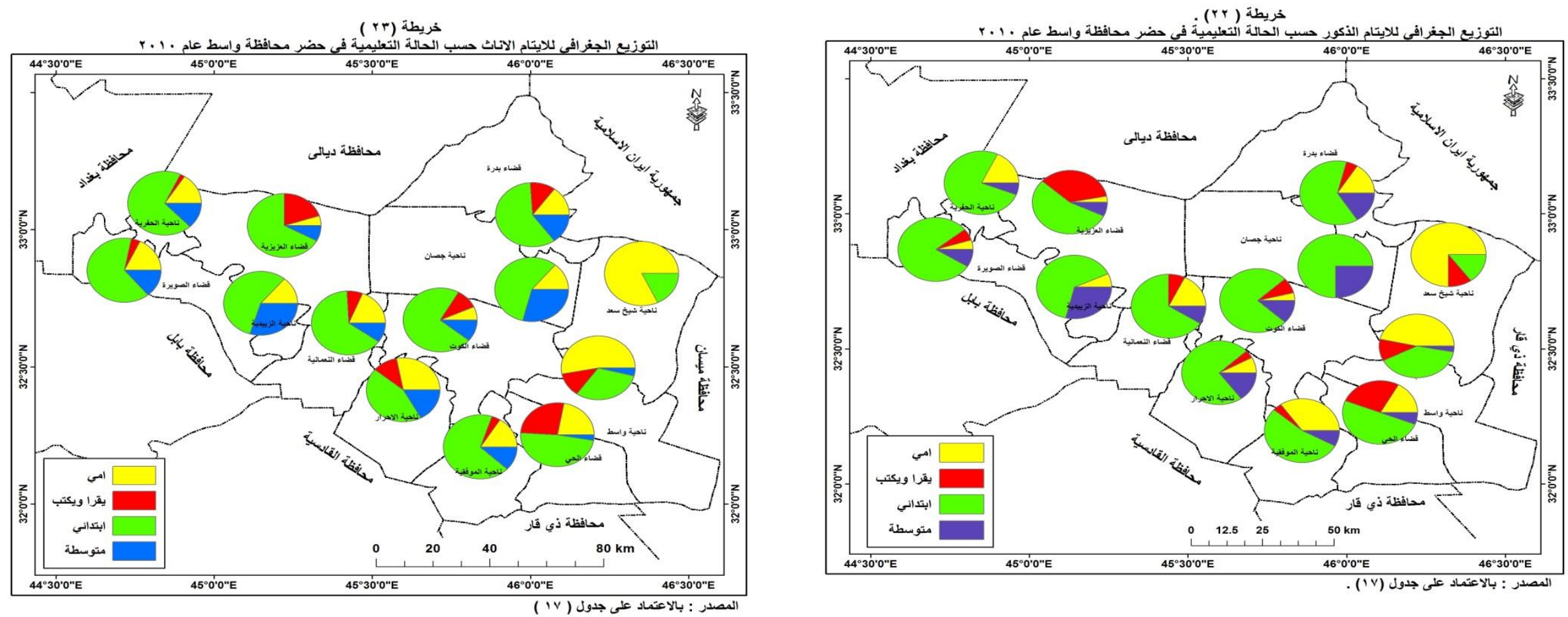


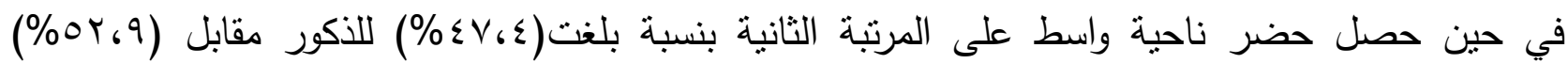

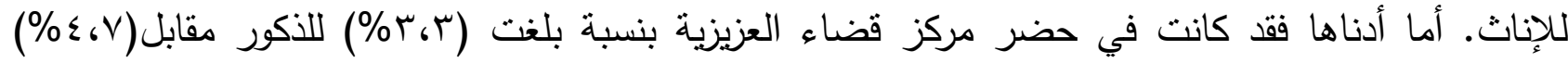

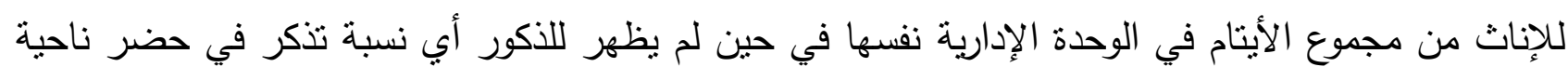

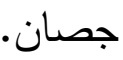
أما الأيتام الذين كان تحصيلهم الدراسي القراءة والكتابة فقط (*) فقد بلغت نسبتهم( (7، ـ (\%) من مجموع

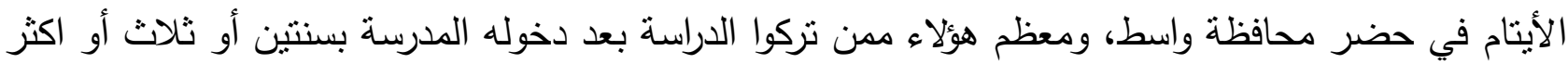
ولم يكملوا المرحلة الابتدائية ، حيث ان ظروفهم الاقتصادية والمعيشية المندنية اضطرتهم إلى دخول بعض منهم

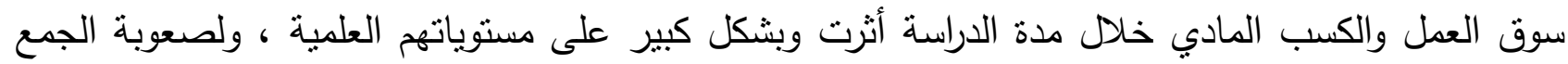

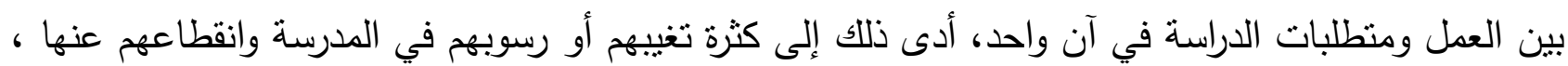

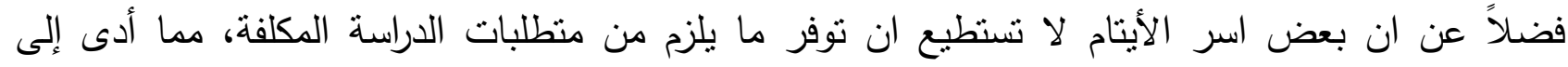

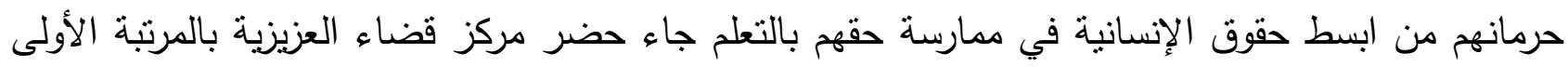

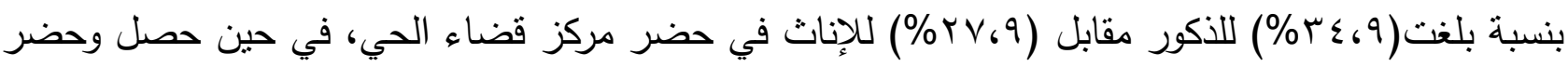

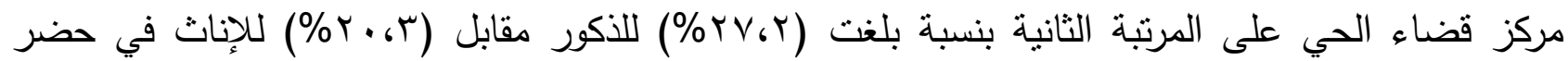

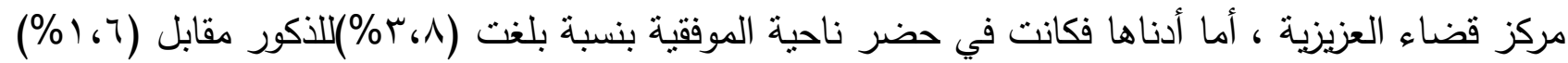

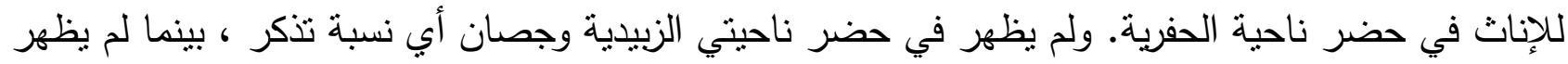
للاكور في حضر ناحية الحفرية أي نسبة تذكر، كذلك لم يظهر للإناث في حضر ناحية شيخ سعد أي نسبة تذكر .

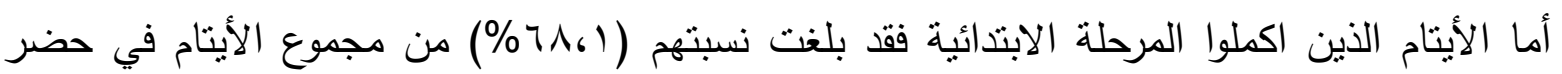

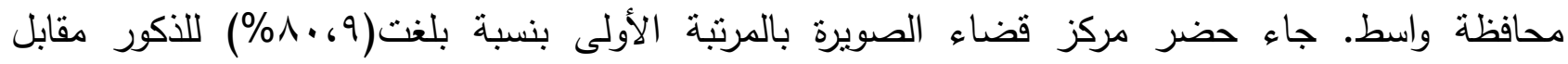
(\%VY،0)

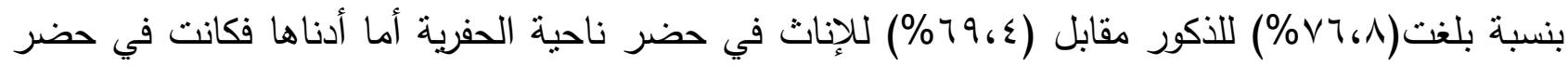


ناحية شيخ سعد بنسبة بلغت(10\%) للذكور مقابل (r/1\%) للإناث من مجموع الأيتام في الوحدة الإدارية نفسها.

أما الأيتام الذين اكملوا المرحلة المتوسطة فقد بلغت نسبتهم (V، • (\%) من مجموع الأيتام في حضر

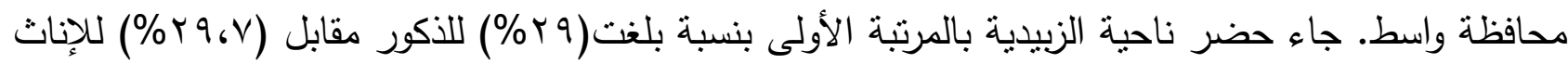

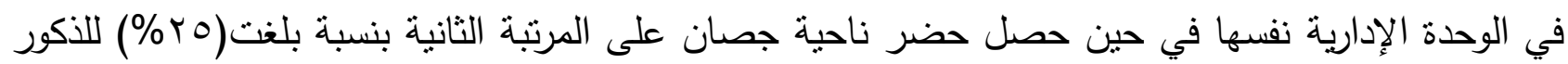
مقابل (Y)،Y\%) للإناث في الوحدة الإدارية نفسها، أما أدناها فكانت في حضر ناحية واسط بنسبة

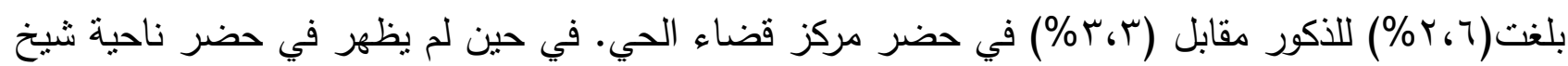

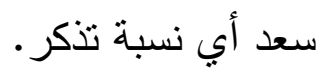

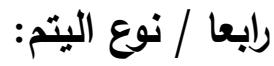

اذا ما فقدت الأسرة احد الوالدين أو كليهما بسبب الوفاة، فان له تأثير على تربية الطفل وتوجيهه لان

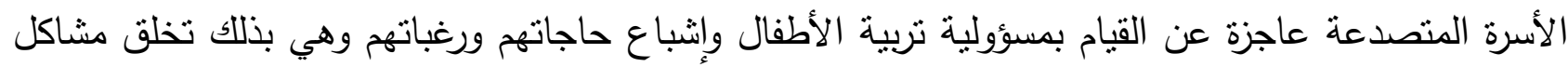
تؤثر على مجرى حياتهم المستقبلية. ان وفاة الأب من المؤثرات المهمة في حياة الطفل، بما يمثلكه من فقدان جانب مهم من الإعانة المنوفرة

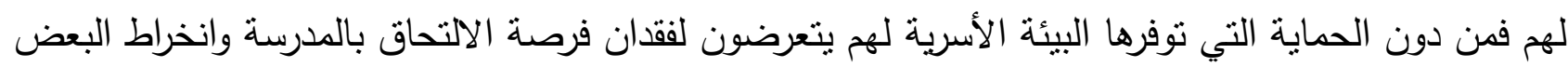

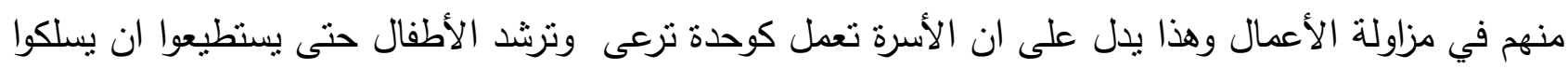
طريق الحياة بأنفسهر (xix).

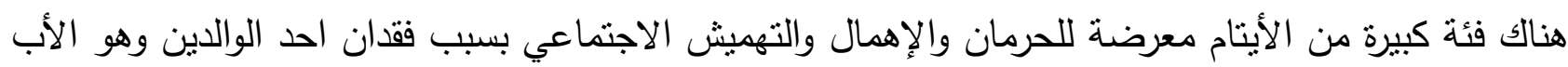

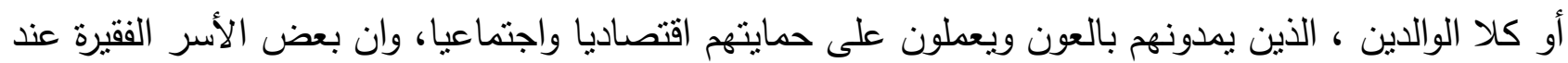
فقد الأب تدفع بالطفل ان يتحمل أعباء أسرته في سن مبكرة(x). تنين من جدول (0) والخريطة(^)(9) ظهور نوعين من اليتم الاول، فقدان الأب والأخر فقدان كلا

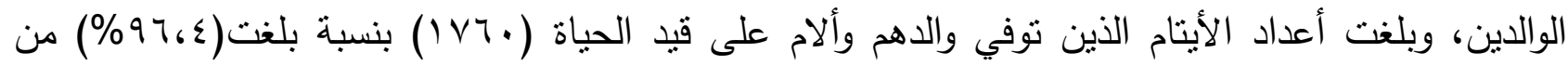
مجموع الأيتام في حضر محافظة واسط. 
وتم حصرهم في ثلاثة مستويات على مستوى الوحدات الإدارية في حضر محافظة واسط وكالاتي:

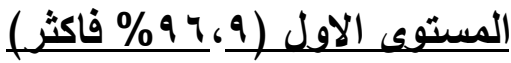

ضم هذا المسنوى نسع وحدات إدارية تمنلت في حضر نواحي كل من واسط والموفقية والأحرار وحضر

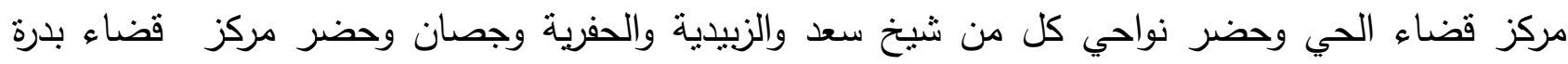
بنسب بلغت (T)

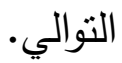

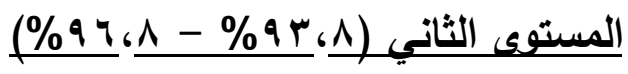

ضم هذا المستوى ثلاث وحدات إدارية تمثلت في حضر مراكز أقضية كل من الصويرة والكوت والعزيزية

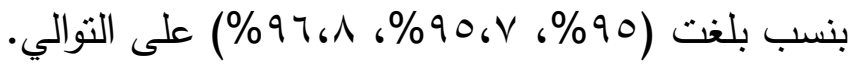

جدول (ن)

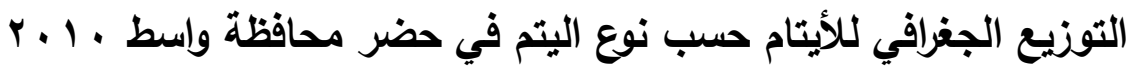

\begin{tabular}{|c|c|c|c|c|c|c|c|}
\hline \multicolumn{2}{|c|}{ المجموع } & \multicolumn{2}{|c|}{ كلا الوالدين متوفي } & \multicolumn{2}{|c|}{ الاب متوفي } & \multirow{2}{*}{ الوحدات الإدارية } & \multirow{2}{*}{$ت$} \\
\hline$\%$ & عدد & $\%$ & عدد & $\%$ & عدد & & \\
\hline $1 \ldots$ & $q T V$ & $\varepsilon_{6}$ & $\varepsilon$. & $90 . \mathrm{V}$ & $\Lambda \Lambda V$ & مركز قضاء الكوت & 1 \\
\hline $1 \ldots$ & Vr & $r_{6} V$ & r & $9 V_{6} \mathrm{r}$ & vi & ناحية واسط & r \\
\hline $1 \ldots$ & $\leqslant Y$ & - & - & $1 \ldots$ & $\varepsilon r$ & ناحية شيخ سعد & $r$ \\
\hline $1 \ldots$ & $0 \leqslant$ & 9.4 & 0 & $9.6 \mathrm{~V}$ & $\leqslant 9$ & 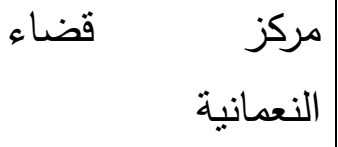 & $\varepsilon$ \\
\hline $1 \ldots$ & $\leq 0$ & $T_{6} T$ & 1 & $9 V_{6} \Delta$ & $\varepsilon \varepsilon$ & ناحية الاحرار & 0 \\
\hline
\end{tabular}




\begin{tabular}{|c|c|c|c|c|c|c|c|}
\hline $1 \cdots$ & 99 & $r_{61}$ & r & 98.9 & $9 \vee$ & مركز قضاء الحي & 7 \\
\hline $1 \cdots$ & rᄉ & $r_{67}$ & 1 & $9 V_{6} \varepsilon$ & rv & ناحية الموفقية & V \\
\hline $1 \cdots$ & Ir. & 0 & 7 & 90 & $11 \varepsilon$ & مركز قضاء الصويرة & $\Lambda$ \\
\hline $1 \cdots$ & $0 \leqslant$ & - & - & $1 \cdots$ & $0 \leqslant$ & ناحية الزبيدية & 9 \\
\hline $1 \cdots$ & $r \leqslant \Lambda$ & $r_{6}$ & $\Lambda$ & 9761 & $r \leq$. & مركز قضاء العزيزية & 1. \\
\hline $1 \cdots$ & $\wedge 1$ & - & - & $1 \cdots$ & $\wedge 1$ & ناحية الحفرية & 11 \\
\hline $1 \ldots$ & r. & - & - & $1 \ldots$ & r. & مركز قضاء بدرة & ir \\
\hline $1 \ldots$ & $1 \varepsilon$ & - & - & $1 \cdots$ & $1 \varepsilon$ & ناحية جصان & M \\
\hline $1 \cdots$ & 1Nro & $r_{67}$ & 70 & $97, \varepsilon$ & 187. & & المب \\
\hline
\end{tabular}

المصدر : مجلس محافظة واسط ، قسم المعلومات ، بيانات غير منشورة، • ( ب

خريطة (Yv)

خريطة (9) - (9) - ( )

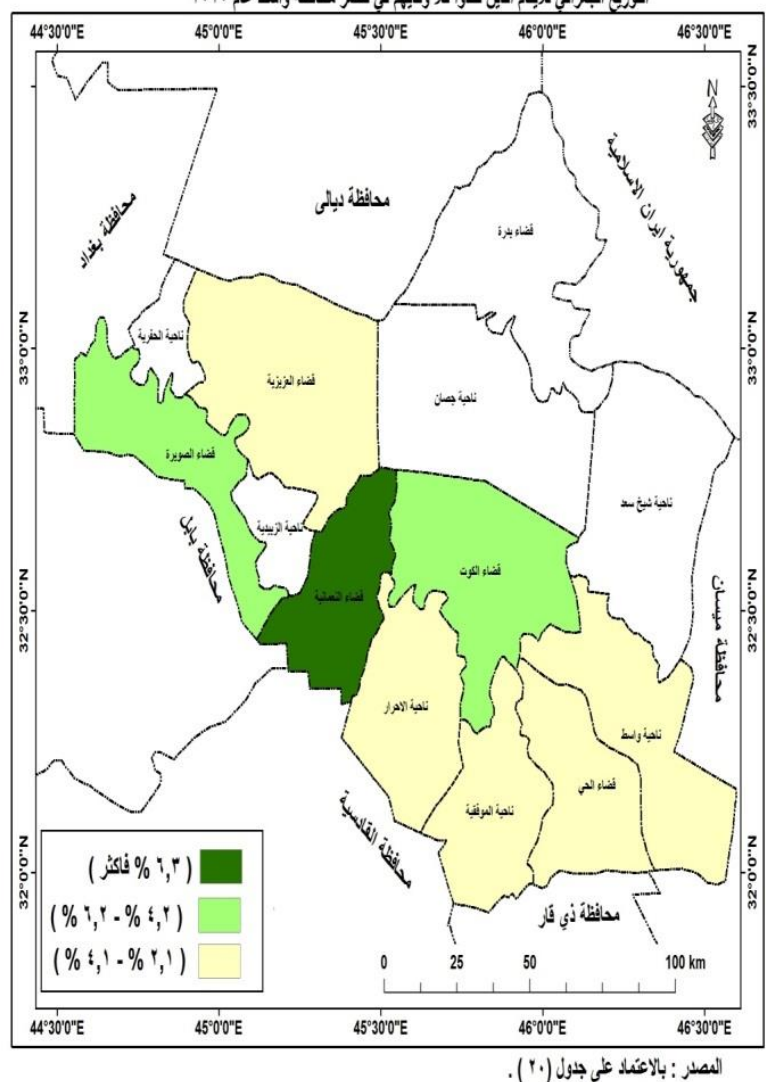

$(\wedge)$

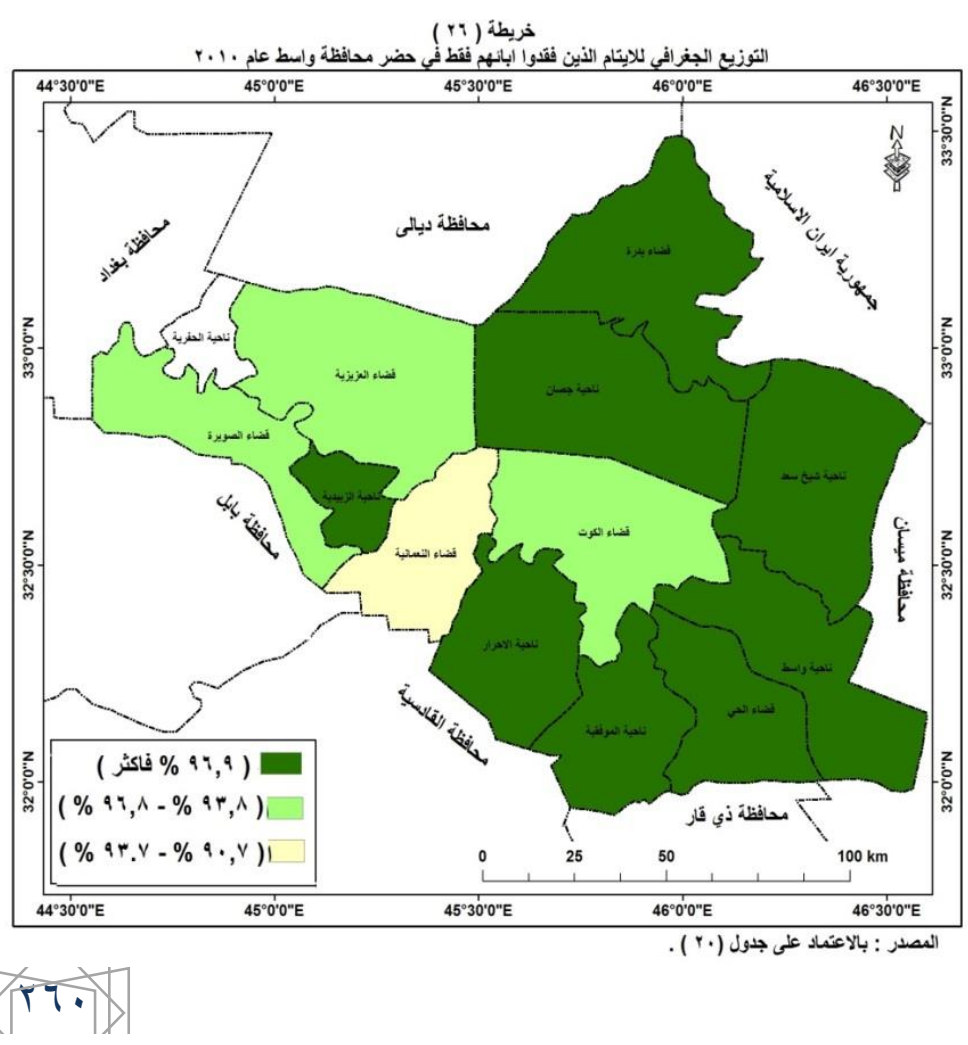

المصدر : بالاعتماد على جدول (0) 


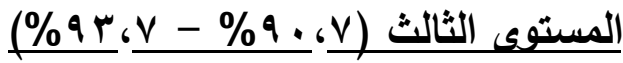

ضم هذا المستوى وحدة إدارية تمنلت بحضر مركز قضاء النعمانية حيث شكلت نسبة (V، •9\%) من مجموع الأيتام في الوحدة الإدارية نفسها. أما النوع الثاني من اليتم والمتمنل بوفاة كلا الوالدين حيث بلغت الادان أعداد الأيتام ضمن هذا النوع من اليتم (70) يتيماً بنسبة بلغت (T، T\%) من مجموع الأيتام في حضر محافظة واسط وكما في خريطة

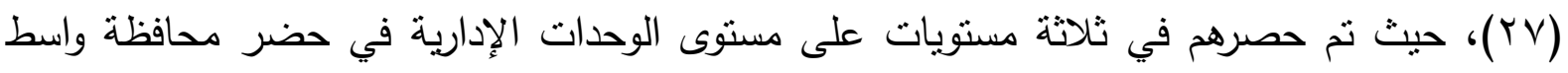
وكالاتي:

\section{المستوى الاول (بّ، \% فاكثر)}

ضم هذ المستوى وحدة إدارية واحدة هي مركز قضاء النعمانية الني شكلت نسبة (T،9\%\%) من مجموع الأيتام في الوحدة الإدارية نفسها.

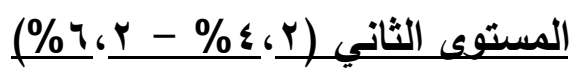

ضم هذا المستوى وحدتين إداريتين هما مركز قضائي كل من الكوت والصويرة بنسب بلغت

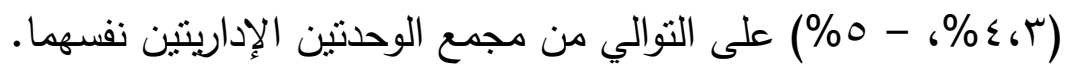
المستوى الثالث(1)

ضم هذا المستوى خمس وحدات إدارية تمنلت في مركز قضاء الحي وحضر نواحي كل من

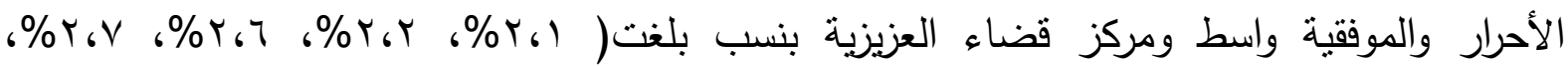

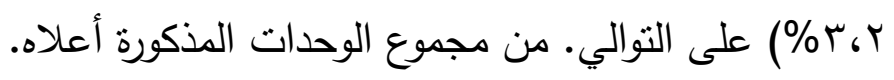

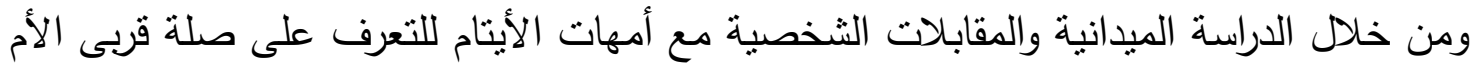

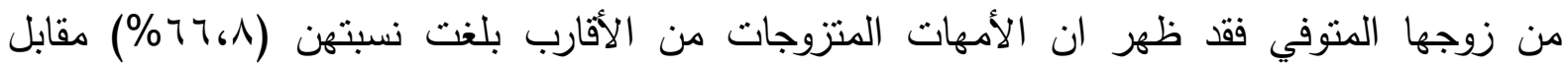

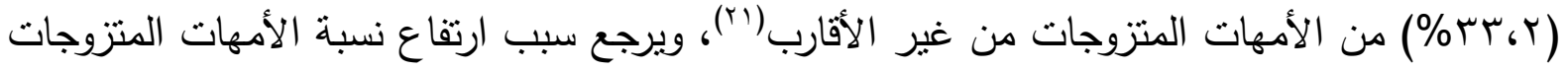

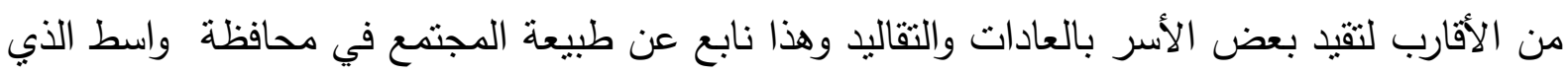

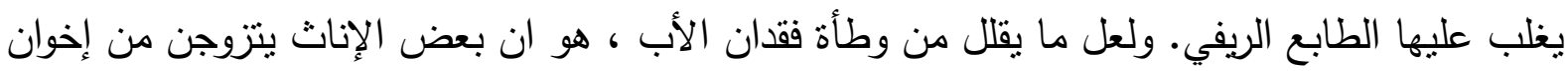


أو أقارب الزوج المتوفى وقد يكون في اغلب الأحيان سبب زواج اخ الزوج المتوفى من زوجة أخيه العناية و الاهتمام بشؤونهم كي يعوض عن فقد والدهم المتوفى . لإنيان

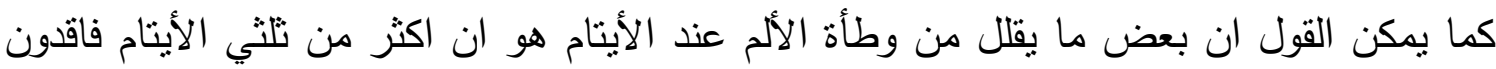

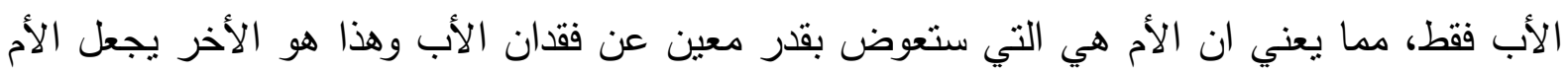

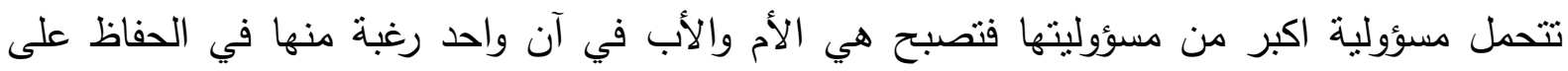

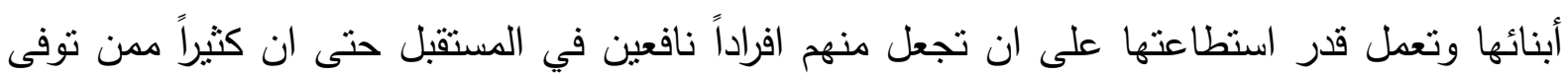

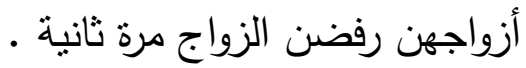

\section{الاستنتاجات و المقترحات}

أولاً: الاستتناجات

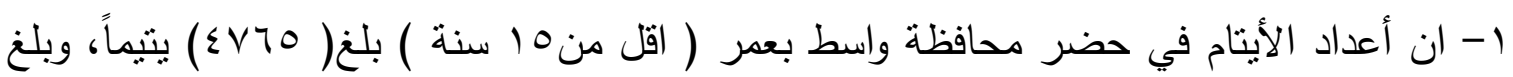

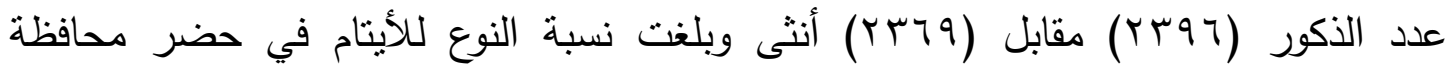

$$
\text { واسط) (1، 1. (1). }
$$

r- بلغ عدد الأيتام المهرين القادمين من مختلف الدحافظات العراقية إلى حضر محافظة واسط

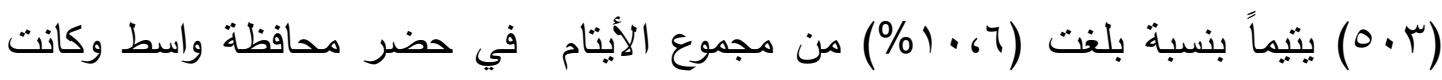

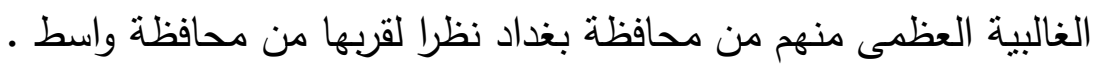

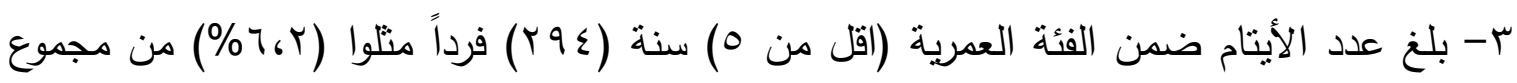

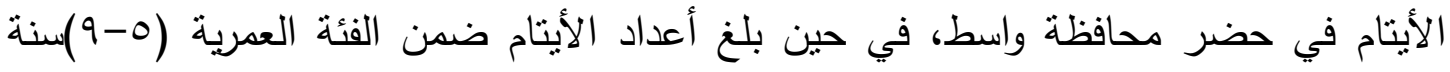

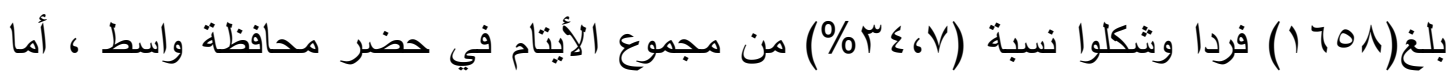

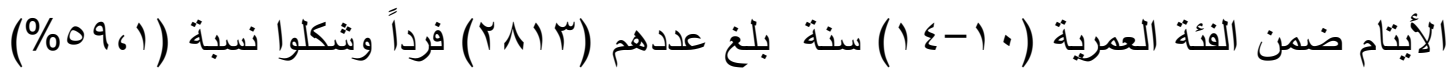
من مجموع الأيتام في حضر محافظة واسط. 
ع- تبين من خلال الدراسة ، ان اهم أسباب عدم إكمال بعض الأيتام دراستهم هو سوء الأوضاع

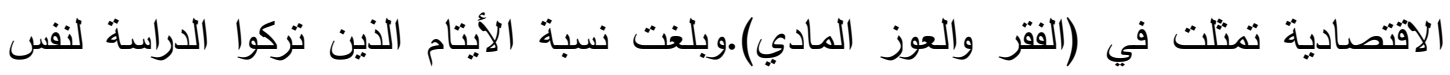
السبب (0، 00\%) وهي اكثر من نصف مجموع الأيتام الذين تركوا الدراسة .

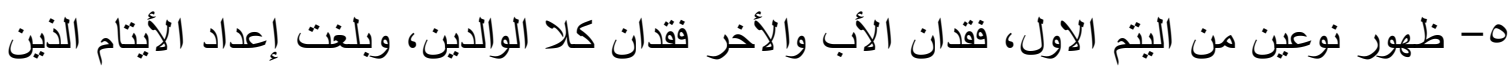

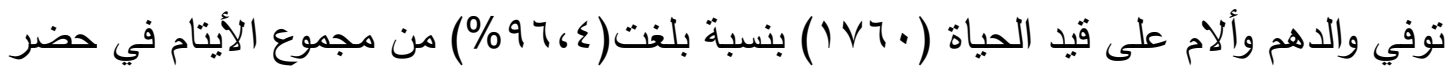

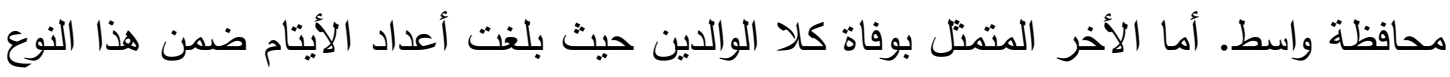

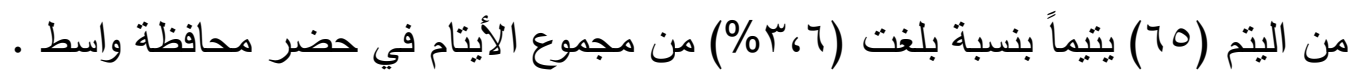


ثانيا: المقترحات

1- رفع المستوى المعاشي لأسر الأيتام الفقيرة وتحسين مستوى الخدمات المقدة لهم للحد من

ظاهرة

من خلال تفعيل دور شبكة الحماية الاجتماعية وشمول جميع اسر الأيتام المحرومة فعلا لإثباع حاجتهم من دون تمبيز

r-ضرورة توجيه الاهنمام بشكل اكبر للتعليم ومؤسساته المختلفة، لاسيما المدارس الابتدائية

والمتوسطة لجذب الأيتام نحوها واستمرارهم فيها ومعالجة تسرب الطلاب منها من خلال

تقديم الحوافز المادية والمعنوية.

ب-توجيه عناية خاصة بالأيتام من قبل المؤسسات الحكومية والدينية والأهلية والأقارب من خلا تقديم المساعدات المادية الكافية بحيث تغني بعض اسر الأيتام من دفع أطفالها إلى

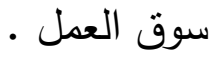


الهوامش والتعليقات

(1) فتحي محمد ابو عيانة ، مشكلات السكان في الوطن العربي ، دار الكوفة الجامعية.ص بـ (1)

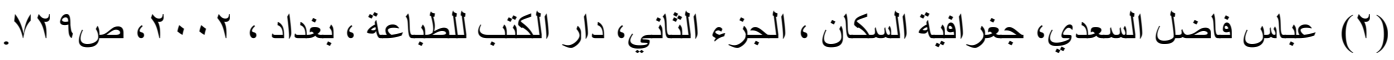

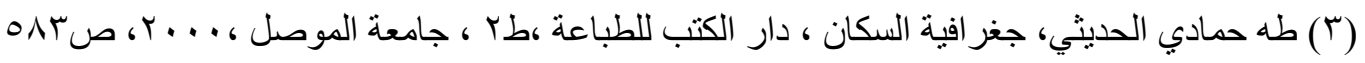
(') فيصل محمد عليوي التميمي ، التهجير القسري و أثناره الاجتماعية على الأسرة المهجرة (در اسـة ميدانيـة في محافظة

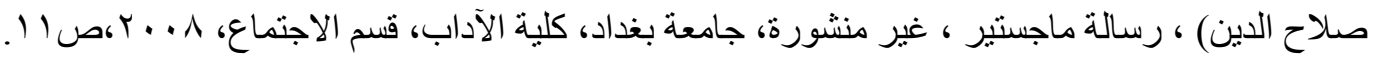

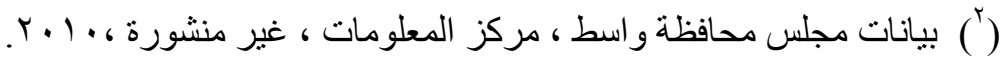

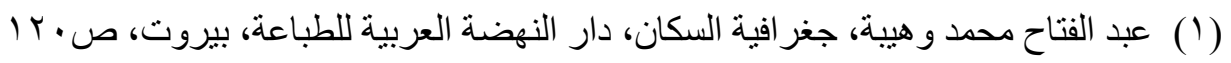

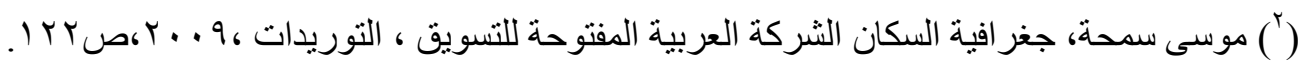

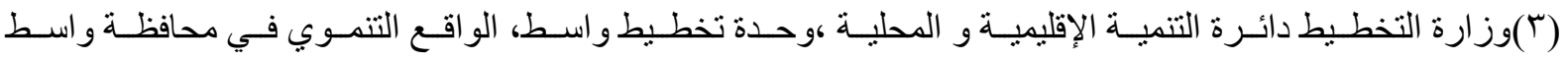

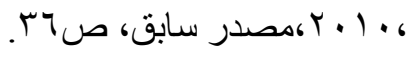

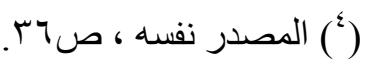

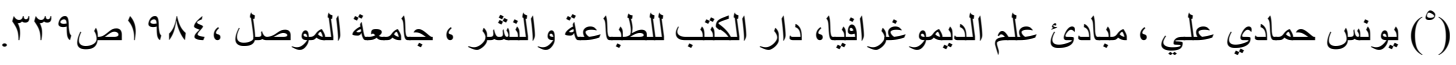

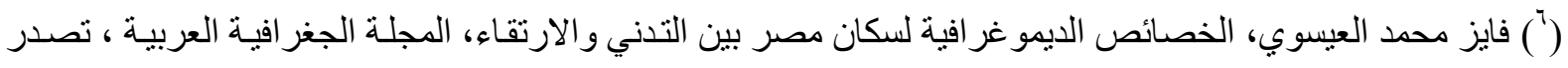

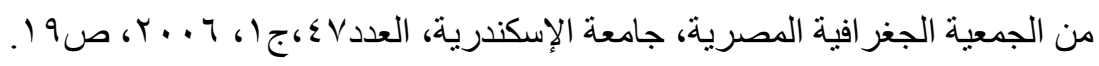

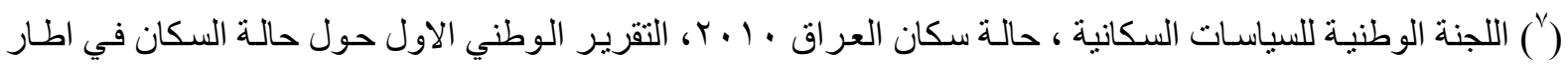
توصيات مؤتمر القاهرة للسكان " الأهداف الإنمائية الألفية" ، 11 ـ ؟، صعء ـ.

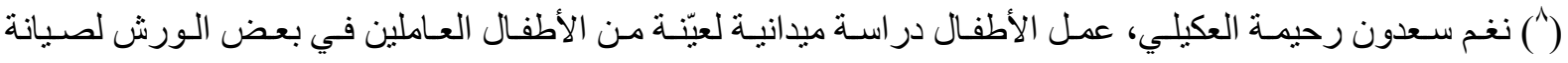

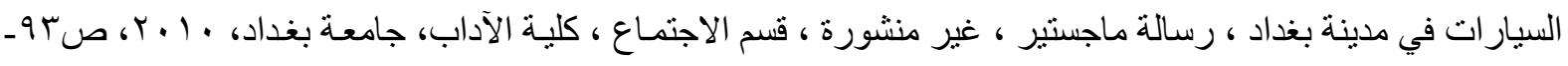

(9) وزارة التخطبطو التعـاون الإنمائي، الجهاز المركزي للإحصـاء وتكنلوجيـا المعلومـات ، مسـح الأحوال المعيثية في

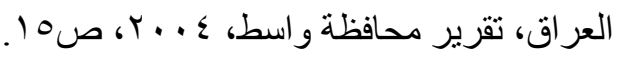
( • ' اخلاص زكي فرج، تسرب التلاميذ في المرحلة الابتدائية ، الأسباب و المعالجات مجلة البحوث و الدر اسات و التربويـة

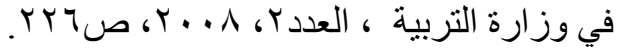

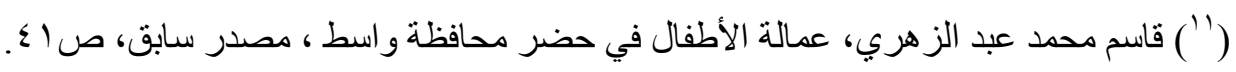




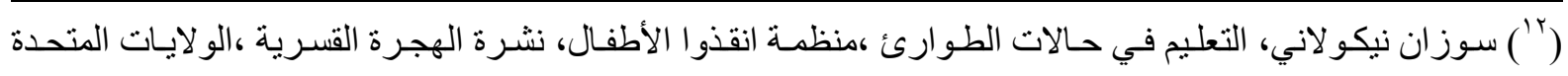

N

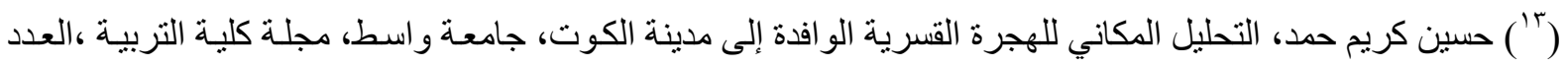

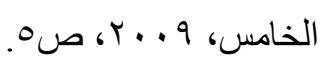

(*) ان لتعليم القر اءة و الكتابة أهمية بالغة في التعامل مع المجتمع، حيث عقت الأمم المتحدة العديد من الاتفاقيات الدولية

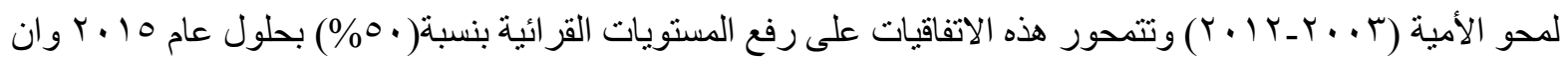
الرفع من المستويات القر ائية تحتل مكانة هامة ضمن الأهداف الإنمائية الألفية للحد من الفقر والتهميش الاجنماعي.

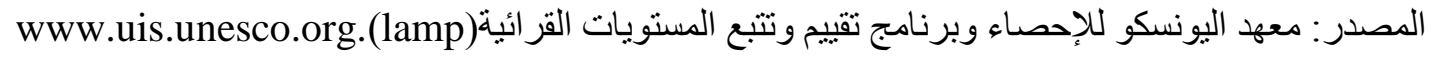

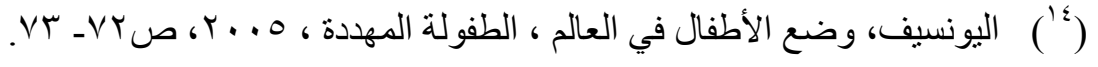

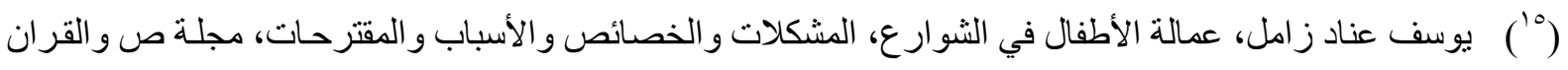

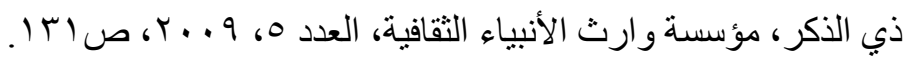

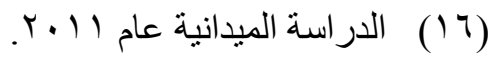




\section{قائمة المصادر}

1- فتحي محمد ابو عيانة ، مشكلات السكان في الوطن العربي ، دار الكوفة الجامعية.

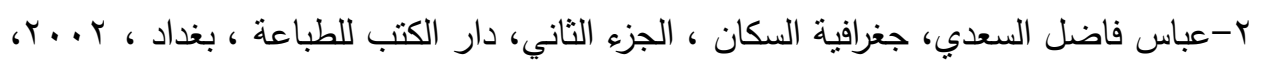

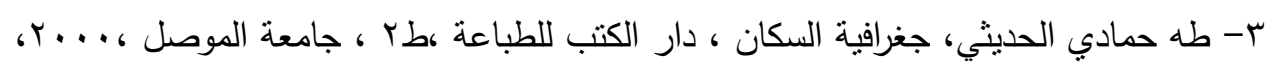
ع-فيصل محمد عليوي التميمي ، التهجير القسري وأثناره الاجتماعية على الأسرة المهجرة (دراسة ميدانية في محافظة المانة

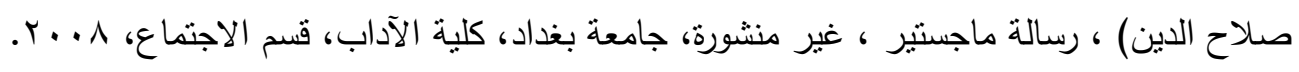

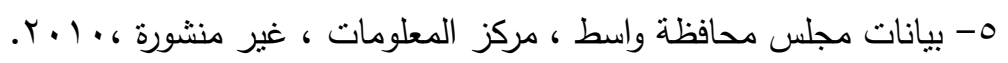

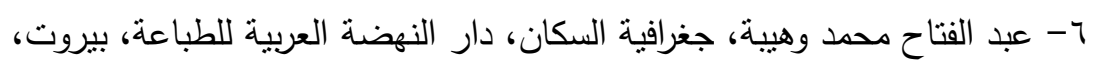

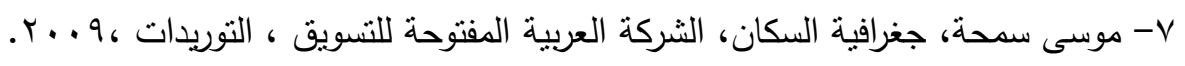

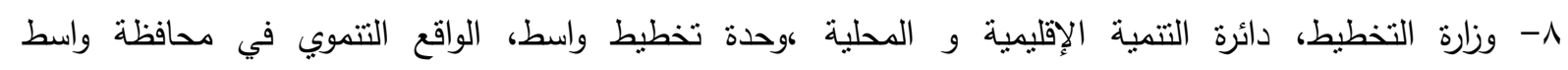

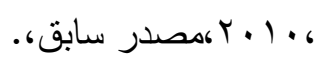
9- المصدر نفسه ، 6.

• ( - يونس حمادي علي ، مبادئ علم الديموغرافيا، دار الكتب للطباعة والنشر ، جامعة الموصل ، عـ191.

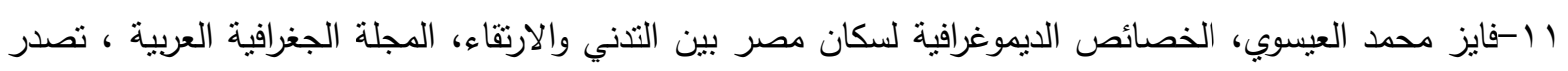

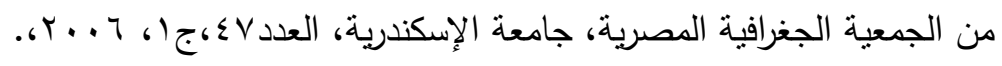

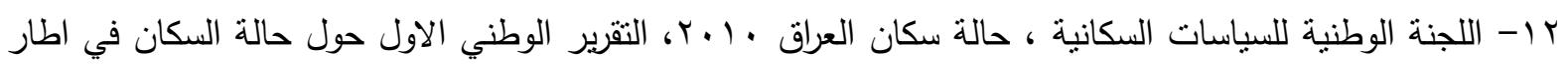

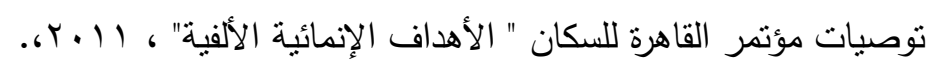

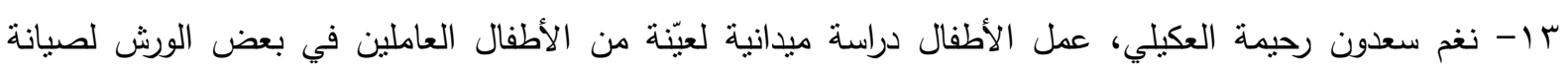

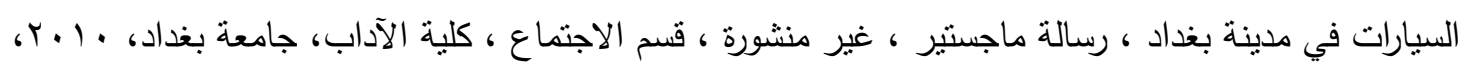

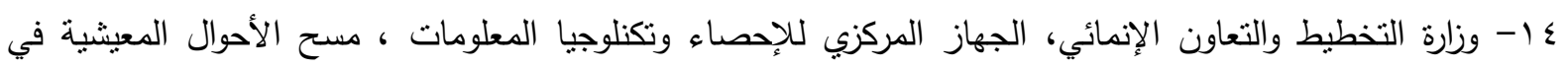

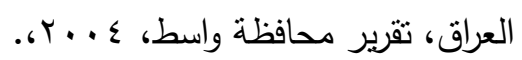
1 - اخلاص زكي فرج، تسرب التلاميذ في المرحلة الابتدائية ، الأسباب والمعالجات مجلة البحوث والدراسات والتربوية

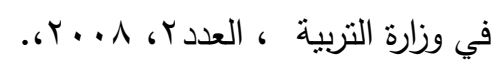
7 ا 1 - قاسم محمد عبد الزهري، عمالة الأطفال في حضر محافظة واسط ، رسالة ماجستير غبر منشورة، جامعة واسط كلية

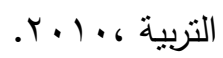




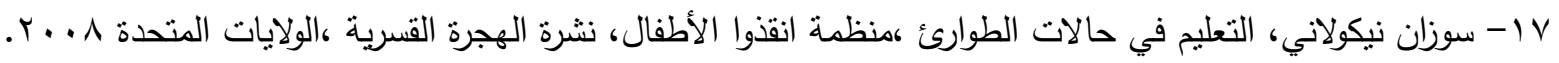
1 ا - حسين كريم حمد، التحليل المكاني للهجرة القسرية الوافدة إلى مدينة الكوت، جامعة واسط، مجلة كلية التربية، العدد

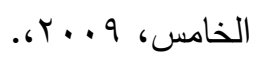
19

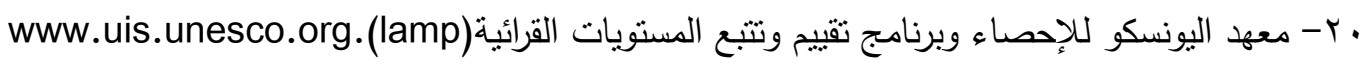

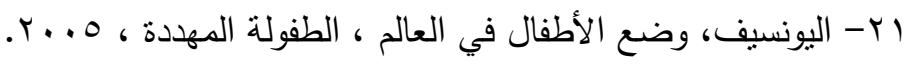
ب ب- - يوسف عناد زامل، عمالة الأطفال في الثوارع، المشكلات والخصائص والأسباب والمقترحات، مجلة ص والقران

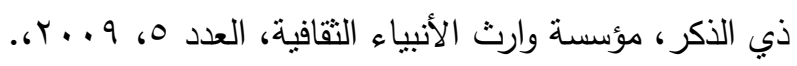

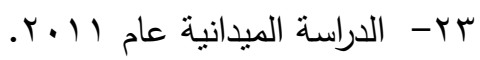

